\title{
The Value of Negotiating Cost-Based Transfer Prices
}

Anne Chwolka, Department of Management and Economics, Otto-von-Guericke-University Magdeburg, Germany, E-mail: chwolka@ovgu.de Jan Thomas Martini, Department of Business Administration and Economics, Bielefeld University, Germany, E-mail: tmartini@wiwi.uni-bielefeld.de

Dirk Simons, Department of Accounting, Business School, Mannheim University, Germany, E-mail: simons@bwl.uni-mannheim.de

\begin{abstract}
This paper analyzes the potential of one-step transfer prices based on either variable or full costs for coordinating decentralized production and quality-improving investment decisions. Transfer prices based on variable costs fail to induce investments on the upstream stage. In contrast, transfer prices based on full costs provide strong investment incentives for the upstream divisions. However, they fail to coordinate the investment decisions. We show that negotiations prevent such coordination failure. In particular, we find that the firm benefits from a higher degree of decentralization so that total profit increases in the number of parameters being subject to negotiations.
\end{abstract}

Keywords: transfer pricing, centralized management, decentralized management, investment, product differentiation, negotiations

Manuscript received April 30, 2009, accepted by Rainer Niemann (Accounting) May 31, 2010.

\section{Introduction}

In the literature, different transfer-pricing schemes are recommended depending on the purpose they are intended for. On the one hand, twostep transfer prices consisting of a unit price compensating for variable production costs and an up-front lump-sum payment to cover fixed costs are suggested for the purpose of coordinating investment and production activities within divisionalized firms (e.g., Drury 2004: 900). On the other hand, the OECD recommends among others a cost-plus scheme for international taxation (OECD 1999: II-11). Empirically, one-step costbased transfer pricing prevails in business practice (see Section 2). However, it is well known from the literature that cost-based types of transfer prices exhibit significant disadvantages with respect to investment incentives in decentralized settings. Taking into consideration that these investments constitute a crucial strategic competitive advantage, finding an adequate transfer-pricing policy is an important managerial issue. As an example, consider today's markets where firms have the opportunity to attract customers' attention by product differentiation. The responsibility for product improvements and development or for ensuring high quality is typically placed not on one but on several divisions. Plausibly, improving the quality of the final product is achieved by joint activities of the divisions, meaning that in divisionalized firms coordination of such kind of activities is necessary in order to exploit synergistic effects.

The goal of our paper is to analyze the investment incentives generated by one-step cost-based transfer prices. Our theoretical analysis builds on the empirical fact that these transfer prices prevail in business practice. We start by replicating the well-known investment distortions for variable cost-based and full cost-based transfer prices. Coupled with the empirically observable dominance of cost-based transfer prices this is the motivation for analyzing the potential of negotiations for mitigating the investment incentive problem by varying the extent of negotiations.

The major innovation of our paper is that we do not only account for interstage but also for intrastage dependencies of the divisions' investment decisions. This means that we analyze interdependencies across the stages - as it is commonly done in the literature - as well as goal conflicts between 
divisions on the same stage. This modification enables us to analyze interesting coordination issues on the upstream stage and to demonstrate how negotiations between the divisions and the extent of delegation influence the performance of transfer pricing. In doing so, we also resolve the dichotomy of cost-based and negotiated transfer prices. Moreover, we do not conceive transfer pricing as a separate incentive system which can be optimized in isolation. Rather, we consider the assignment of decision rights within the firm also as variable. We demonstrate that central management may reach better coordination by delegating more - rather than fewer - aspects of the transferpricing system, which has important managerial implications.

The remainder of the paper is organized as follows. Section 2 provides a brief literature review. The organizational setting is described in the third section together with the underlying assumptions. Section 4 contains the model results for different settings. Initially, the first-best solution is derived. Subsequently, we demonstrate that none of the considered schemes is able to induce investments in all of the three divisions. Moreover, transfer pricing based on full costs is prone to suffer from coordination failure. In this context, introducing negotiations on both the investments and the transfer prices is shown to ensure optimal coordination. The paper concludes with managerial implications. Appendices A and B contain the proofs and an example, respectively. Additional explanations concerning the negotiations under transfer pricing based on full costs are provided in Appendix C.

\section{Related literature}

Related literature falls into an empirical and a theoretical strand. From an empirical perspective, it can be confirmed that one-step cost-based transfer-pricing schemes prevail in business practice. This observation is supported by the survey of empirical studies in Horngren, Datar, and Foster (2006: 774). It is confirmed and extended by Ernst \& Young (2001: 19) who document the predominance of cost-based transfer-pricing schemes irrespective of the type of transaction in the context of international taxation. It is valid to build on the findings of Ernst \& Young (2001) in our context because Ernst \& Young (2003: 17) find that
80 percent of 641 multinational parent companies use the same transfer price for managerial and tax purposes. Czechowicz, Choi, and Bavishi (1982: 59) find a corresponding share of 84 percent. Furthermore, although two-step transfer prices provide more flexibility by allowing for a lump-sum transfer payment to cover fixed costs, empirical evidence suggests that the prevalence of two-step transfer prices is extremely low: According to Tang (1993: 71), only one percent of 143 firms employ two-step schemes to price national or international transfers. With respect to the question of whether transfer prices are administered or negotiated, the survey by Horngren, Datar, and Foster (2006: 774) seems to document a rather low prevalence of negotiated transfer prices ranging between 11 and 26 percent. Yet, Eccles points out a shortcoming of many empirical studies which do not consider negotiations given a certain pricing scheme. Accordingly, referring to firms that transfer at a profit markup based on a given scheme, Eccles (1985: 43) states that "seventy-two percent of these firms said yes" when asked "if some kind of negotiation was also involved."

From a practical as well as a theoretical perspective, coordination is an important function of transfer prices, see, e.g., Drury (2004: 883) or Grabski (1985: 35). This becomes evident with the introduction of relation-specific investments, see, e.g., the seminal papers of Edlin and Reichelstein $(1995,1996)$ or Holmstrom and Tirole (1991) where the hold-up problem is highlighted. Extensions have been made by Baldenius (2000), Wielenberg (2000), Anctil and Dutta (1999), and Baldenius, Reichelstein, and Sahay (1999). All these papers focus on freely negotiated transfer prices, i.e., without a given pricing scheme, or on the comparison of negotiated and cost-based transfer prices. Sahay (2003) analyzes additive versus multiplicative markups on costs, whereas Lengsfeld, Pfeiffer, and Schiller (2006) analyze the comparative advantages of transfer prices based on actual and standard costs. All these contributions assume investments inducing a reduction of production costs or an increase in sales revenue. The considered investments might be called "egoistic" since it is assumed that it is the investing division which directly benefits from the induced returns (see Che and Hausch 1999, for a similar terminology).

Similar to the papers cited above, we consider the problem of motivating divisional investments 
via transfer prices. We also rely on negotiations to overcome interest conflicts between the divisions. However, we do not distinguish between cost-based transfer prices on the one hand and negotiated transfer prices on the other. Instead, we follow an integrated perspective by extending the solution space provided by administered cost-based transfer prices by inter-divisional negotiations on the specification of the given pricing scheme. Another difference of our setting is that the divisions invest knowing the specified transfer price and that each investment's productivity depends on the other investment levels. Thus, the problem of coordinating investments has to be solved in the first place instead of a hold-up problem potentially occurring after the investments have been made.

Only a few other papers have incorporated cooperative - instead of egoistic - investments into transfer-pricing settings. Our investment setting is similar to Johnson (2006) or Chwolka and Simons (2003). In contrast to their approaches, we concentrate on transfer prices instead of sharing rules and incorporate negotiations. Moreover, analyzing three divisions enables us to illustrate two different kinds of coordination problems: On the one hand the coordination among the upstream divisions which is typically neglected in the literature and on the other hand the "traditional" coordination problem between upstream and downstream divisions.

The contribution of our paper results from the introduction of a second upstream division. Given the traditional setting with one upstream and one downstream division, it seems obvious that the firm faces an overinvestment problem on the upstream production stage when transfer prices cover full costs plus a multiplicative markup. In our extended setting, we not only confirm this intuition but show also that an underinvestment problem may occur as well. More importantly, we show that ensuring investments and production does not only require solving the coordination problem between the production stages, but also between the divisions on the same stage. Accordingly, we examine how negotiations over the investment levels induces coordination on the upstream production stage. We extend the analysis by demonstrating that the firm benefits from having the upstream divisions not only negotiate investments but also transfer prices.

\section{Model description}

We consider a firm consisting of three investment centers $D_{i}, i \in\{1,2,3\}$, being subordinated to headquarters, $H Q$. $H Q$ confines itself to installing a transfer-pricing system - where transfer prices do not necessarily have to be administered - for coordinating the investment centers. We assume that transfer prices have to be defined before any activities take place. One justification for this assumption are requirements demanded by tax authorities or other legal requirements. $H Q$ delegates any operative decision to the divisions, including those referring to the investment levels $I_{i}$. All divisions have access to external factor markets where they procure the required raw materials and goods - except for the intermediate products which are exclusively traded between the divisions. The upstream divisions $D_{1}$ and $D_{2}$ deliver intermediate goods or services to the downstream division $D_{3}$ and are compensated via transfer-price payments. The downstream division completes the product and sells it to an external market. These general assumptions are fairly standard and depicted in Figure 1 where $c_{i}$ symbolizes the variable costs per production unit accruing in division $D_{i}$ before accounting for transfer payments, whereas $t_{1}$ and $t_{2}$ are the transfer prices at which each product unit of $D_{1}$ and $D_{2}$ is valued. $I_{i}$ denotes the investment level and equals the expected investment costs. $x$ is the production and sales quantity, and $p(\cdot)$ is the expected sales price.

In the following, we explain the assumptions in more detail. We assume that divisionalization is given. Headquarters is not able to calculate optimal investment levels because it lacks information on productivity parameters. Consequently, $H Q$ delegates the investment and trade decisions to the division managers. Ex post, $H Q$ can neither verify the investment levels nor evaluate their optimality, but can only observe the corresponding actual costs. However, the investment costs resulting from the chosen investment levels are stochastic.

Having a closer look at the divisions, note that from the perspective of organizational theory a major advantage of decentralization is greater flexibility with respect to market demands (see Grabski 1985 for reasons in favor of decentralization). This fact is incorporated in our model by the assumption of information asymmetry between headquarters and the divisions. Further, we assume that the 
division managers are interested in their respective divisional profit. This assumption could be justified by the existence of an according incentive system. The investment-center organization induces self-interested divisional decisions so that any formal or informal agreement between the divisions has to be in the interest of each of the divisions. Communication between the divisions is therefore of no use unless the resulting agreement is self-enforcing. Note that the three divisions - in contrast to $H Q$ - share perfect information as to the transaction under consideration. This assumption is motivated by the fact that the operative divisions have a deeper knowledge of product-specific data as compared to $H Q$.

The two-stage production process is performed by the three divisions as depicted in Figure 1. The intermediate products cannot be sold externally so $D_{1}$ and $D_{2}$ are obliged to deliver their products to $D_{3}$. $D_{3}$, in turn, has to procure these specific intermediate goods from $D_{1}$ and $D_{2}$ because they are not offered on an external market. For analytical convenience, all production coefficients are equal to one. The maximal product quantity $\bar{x}>0$ reflects capacity restrictions, i.e., $x \in[0, \bar{x}]$. As motivated later in the paper, the investments considered here do not affect capacity.

The most important objective of modern firms relying on decision decentralization is to handle the fragmentation of product responsibilities. This holds true especially when the competitive advantage is based on product differentiation. This problem is integrated into our model by focusing on quality-improving investments. Note that the term "investment" has to be interpreted in a wide sense in our paper. We have in mind spendings that are able to increase the customers' willingness to pay, which depends on the product-specific bundle of features (Simon 1989: 1). These investments may be spendings for machines producing at a higher quality level, research and development expenditures implying an improvement of the product's functionalities, or organizational arrangements speeding up service times and thus increasing customer satisfaction.

The interrelated effects of the divisional investments are reflected by the sales price $p$ which depends on the individual investment levels and a random variable $\varepsilon$. We have

$$
\tilde{p}\left(I_{1}, I_{2}, I_{3}\right)=p\left(I_{1}, I_{2}, I_{3}\right)+\varepsilon
$$

with non-negative investment level $I_{i}$ chosen by $D_{i}, i \in\{1,2,3\}$. An example with a specific price function is presented in Appendix B. $\varepsilon$ is a random variable with mean $\mu(\varepsilon)=0$. Thus, the expected price is given by $\mathrm{E}_{\varepsilon}\left[\tilde{p}\left(I_{1}, I_{2}, I_{3}\right)\right]=p\left(I_{1}, I_{2}, I_{3}\right)$. As argued above, the price is increasing in qualityimproving investments. Moreover, we assume that $p$ is strictly concave and bounded; additionally the input factors' contributions to the output cannot be isolated. Formally, we have

$$
\begin{aligned}
& \frac{\partial p\left(I_{1}, I_{2}, I_{3}\right)}{\partial I_{i}}>0, \\
& \frac{\partial^{2} p\left(I_{1}, I_{2}, I_{3}\right)}{\partial I_{i} \partial I_{j}} \neq 0 \quad \forall i, j \in\{1,2,3\} .
\end{aligned}
$$

We assume that the costs resulting from investment level $I_{i}, i \in\{1,2,3\}$, are uncertain and amount to $\tilde{C}_{i}\left(I_{i}\right)=I_{i}+\kappa_{i} \geq 0$, where $\kappa_{1}, \kappa_{2}$, and $\kappa_{3}$ are independent random variables with means $\mu\left(\kappa_{i}\right)=0$. Thus, the expected investment costs are given by $\mathrm{E}_{\kappa_{i}}\left[\tilde{C}_{i}\left(I_{i}\right)\right]=I_{i}$. Actual, i.e., realized, investment costs are denoted by $C_{i}$.

In order to emphasize quality-improving investments we abstract from capacity increases and thus leave the quantity effect on the sales price out of account. Observe that this is a standard assumption, e.g., in the target-costing literature. In business practice, the quantity effect is negligibly small in several environments: For instance, in markets with a high brand loyalty, e.g., luxury goods or certain food products, the price sensitivity is low. Similarly, if the customer has made

Figure 1: Structure of the firm

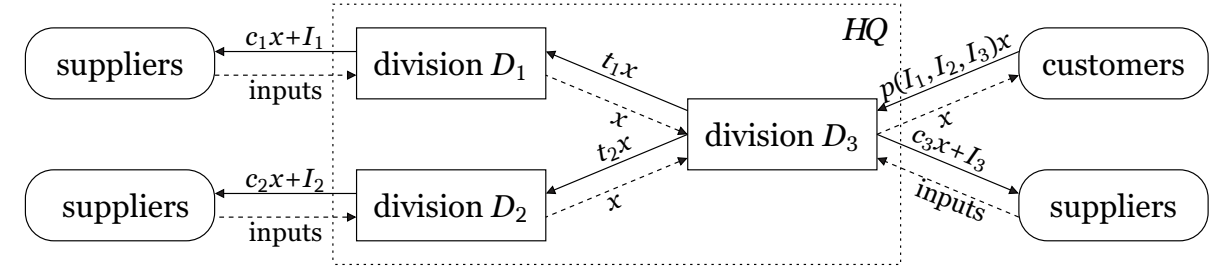


investments in the past, the present buying decision might be predetermined. As an example consider software updates. Generally, this phenomenon arises whenever accessories have to be bought for non-standardized products.

The timing of decisions and actions is as shown in Figure 2. In the first step, $H Q$ chooses a cost-based transfer-pricing scheme, i.e., either scheme $v$ based on variable costs or scheme $f$ based on full costs. Additionally, the parameters determining the chosen scheme respectively the extent of delegation are specified. In the next step, the divisions simultaneously decide on their investment levels $I_{i}$, $i \in\{1,2,3\}$, under perfect information, i.e., each division knows its own as well as the others' decision problems. Subsequently, $D_{3}$ determines the production and sales quantity $x$. Finally, product units are manufactured and sold, the sales price is realized, and the realized investment costs are determined, which allows the calculation of total and divisional profits. We refer to $H Q$ 's decision making as centralized planning which defines the conditions of the subsequent decentralized planning, i.e., investments and production.

We assume all managers and $H Q$ to be risk-neutral. The goal of $H Q$ is to maximize expected total, i.e., firm-wide, profit:

$$
\begin{aligned}
& \Pi\left(I_{1}, I_{2}, I_{3}, x\right) \\
& =\left(\mathrm{E}_{\mathcal{\varepsilon}}\left[\tilde{p}\left(I_{1}, I_{2}, I_{3}\right)\right]-\sum_{i=1}^{3} c_{i}\right) x-\sum_{i=1}^{3} \mathrm{E}_{\kappa_{i}}\left[\tilde{C}_{i}\left(I_{i}\right)\right] \\
& =\left(p\left(I_{1}, I_{2}, I_{3}\right)-\sum_{i=1}^{3} c_{i}\right) x-\sum_{i=1}^{3} I_{i} .
\end{aligned}
$$

Observe that the divisional profits sum up to total profit. Moreover, remember that $c_{3}$ does not account for any transfer prices but symbolizes the costs per unit for externally procured inputs as depicted in Figure 1. We assume a positive contribution margin which may be im- proved by divisional investments. Formally, we have $\Pi(0,0,0, x)>0$ and $\partial \Pi(0,0,0, x) / \partial I_{i}>0$ for $x>0$ and $i \in\{1,2,3\}$.

For the first-best situation, we assume information symmetry between $H Q$ and the divisions. In the second-best situation, we assume that variable as well as realized investment costs are observable and contractible so that the transfer-pricing schemes introduced and analyzed in the following below are feasible. However, $H Q$ is not able to observe the chosen investment level. This information asymmetry is the reason for $H Q$ to delegate decision authority to the divisions and to implement a transfer-pricing system.

\section{Model analysis}

In this section, we first consider the first-best solution. The two following subsections deal with transfer pricing based on variable and full costs, respectively. They deviate from the first-best situation in that there is information asymmetry between $H Q$ and the divisions. We refer to them as the second-best situation. We start the analysis of the second-best situation by replicating the well-known underinvestment problem for variable cost-based transfer prices and the overinvestment problem for full cost-based transfer prices. In particular, the transfer-pricing scheme $v$ is based on variable costs and induces investment incentives only on the downstream production stage. Underinvestment occurs under this scheme since both upstream divisions do not invest. In contrast, scheme $f$ is based on full costs and has the potential to create strong investment incentives on the upstream production stage. Then, however, the transfer price on its own is insufficient to induce coordination among the divisions. We show how negotiations may remedy this defect effectively and may even align upstream divisions with the firm's objective.

Figure 2: Time line

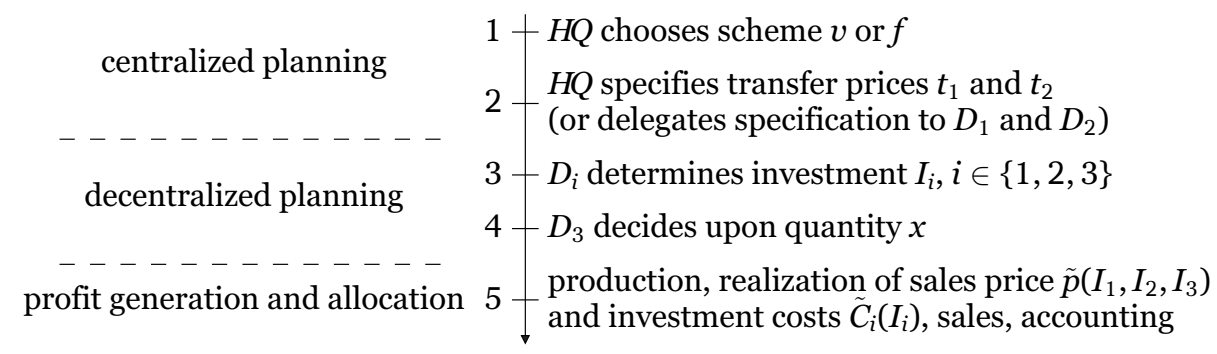




\subsection{First-best situation}

In the first-best situation with information symmetry between $H Q$ and the divisions, $H Q$ is able to determine and enforce optimal divisional investment levels and the optimal product quantity. Proposition 1 states the first-best solution. All proofs are given in Appendix A. In Appendix B we calculate the first-best solution for an example.

Proposition 1. The first-best quantity is $x^{f b^{*}}=\bar{x}$. The first-best investment levels $I_{i}^{f b^{*}}, i \in\{1,2,3\}$, are positive and finite.

With the price-quality relation as defined in equation (1) the corporate objective function is given by (3). The first part of equation (3) represents the total expected contribution margin per product unit. By assumption, this margin is positive for any combination of investment levels. Hence, it is optimal for $H Q$ to set the product quantity to its maximum value.

\subsection{Transfer prices based on variable costs (scheme $v$ )}

Sections 4.2 and 4.3 reflect the second-best situation where $H Q$ delegates decision authority to the divisions and confines itself to administering the transfer-pricing system. As a first step we analyze the investment incentives of transfer prices based on variable costs.

We assume that transfer prices under scheme $v$ are defined by $t_{i}^{v}=\left(1+\gamma_{i}\right) c_{i}, i \in\{1,2\}$, where the multiplicative markup factors $\gamma_{i} \geq 0$ ensure non-negative divisional contribution margins on the upstream production stage. Remember that all division managers are risk-neutral and seek to maximize their expected divisional profits. The divisional objective functions $\Pi_{i}^{v}$ read

$$
\begin{aligned}
\Pi_{i}^{v}\left(I_{1}, I_{2}, I_{3}, x\right) & =\left(t_{i}^{v}-c_{i}\right) x-\mathrm{E}_{\kappa_{i}}\left[\tilde{C}_{i}\left(I_{i}\right)\right] \\
& =\gamma_{i} c_{i} x-I_{i}
\end{aligned}
$$

for the upstream divisions $D_{i}, i \in\{1,2\}$, and

$$
\begin{aligned}
\Pi_{3}^{v}\left(I_{1}, I_{2}, I_{3}, x\right) \\
=\left(\mathrm{E}_{\varepsilon}\left[\tilde{p}\left(I_{1}, I_{2}, I_{3}\right)\right]-\sum_{j=1}^{2}\left(1+\gamma_{j}\right) c_{j}-c_{3}\right) x \\
\quad-\mathrm{E}_{\kappa_{3}}\left[\tilde{C}_{3}\left(I_{3}\right)\right] \\
=\left(p\left(I_{1}, I_{2}, I_{3}\right)-\sum_{j=1}^{2}\left(1+\gamma_{j}\right) c_{j}-c_{3}\right) x-I_{3}
\end{aligned}
$$

for the downstream division. Expected profits of $D_{1}$ and $D_{2}$ equal the difference of the transfer payment and the sum of the variable production and expected investment costs. Divisional expected profits in (4) immediately show that the upstream divisions have no incentive to invest at all under scheme $v$ replicating the underinvestment effect of variable cost-based transfer prices.

In contrast to the upstream divisions, $D_{3}$ receives the actual turnover. In addition to its own variable production and investment costs, $D_{3}$ has to account for the transfer payments to $D_{1}$ and $D_{2}$. Accordingly, it is only optimal for $D_{3}$ to set a positive product quantity, if its expected contribution margin is non-negative. Moreover, inducing a positive investment on the downstream production stage implies a non-negative expected profit for $D_{3}$. This requires sufficiently small markups. We have the following equilibrium in divisional decisions.

Proposition 2. Presume that markup factors $\gamma_{1}$ and $\gamma_{2}$ under scheme $v$ are sufficiently small so that

$$
\begin{aligned}
& \left(\gamma_{1}, \gamma_{2}\right) \in\left\{\left(\gamma_{1}, \gamma_{2}\right) \in \mathbb{R}_{+}^{2}:\right. \\
& \left.p(0,0,0)-\sum_{i=1}^{2}\left(1+\gamma_{i}\right) c_{i}-c_{3} \geq 0\right\}
\end{aligned}
$$

is satisfied. Then, in equilibrium, divisional investments are $I_{1}^{v^{*}}=I_{2}^{v^{*}}=0, I_{3}^{v^{*}}>0$, and the product is marketed, $x^{v^{*}}=\bar{x}$.

With respect to the upstream divisions, transfer prices based on variable costs seem to be inadequate for inducing investments. Accordingly, the underinvestment problem on the upstream production stage has to be managed by other organizational arrangements.

\subsection{Transfer prices based on full costs (scheme $f$ )}

In this section, we analyze transfer-pricing schemes based on full costs with different organizational embeddings. We start by showing that fully administered transfer prices, i.e., without interdivisional negotiations, may result either in an underinvestment or an overinvestment problem. For the overinvestment problem, investment incentives on the upstream production stage are so strong that further coordination in addition to the 
administered transfer prices is needed. We demonstrate how negotiations on the investment levels solve the coordination problem. For further improving the investment levels we introduce fully negotiated cost-based transfer prices which allow for substantial improvements.

\subsection{The divisional decision problems with full cost-based transfer prices}

For positive product quantities, transfer prices based on full costs $\tilde{t}_{i}^{f}, i \in\{1,2\}$, are defined according to

(7) $\tilde{t}_{i}^{f}=\left(1+\omega_{i}\right)\left(c_{i}+\frac{\tilde{C}_{i}\left(I_{i}\right)}{x}\right)$

as full cost plus markup. Otherwise, with no sales, transfer prices are zero. $\omega_{i}$ symbolizes a multiplicative markup factor determining divisional profits. We restrict our analysis to multiplicative markups, because transfer prices with additive markups do not provide sufficiently strong investment incentives for the upstream divisions. Note that due to the uncertainty of the investment costs the transfer prices based on full costs are also random variables. Accordingly, the risk-neutral division managers base their investment decisions on the expected transfer prices $t_{i}^{f}=\left(1+\omega_{i}\right)\left(c_{i}+I_{i} / x\right)$. Calculation of the realized transfer prices requires that the accounting system is able to measure the realized investment costs $C_{i}$ beside the variable costs $c_{i}$ and the quantity $x$.

In case the product is marketed, $x>0$, upstream division $D_{i}$ 's, $i \in\{1,2\}$, objective function under scheme $f$ reads

$$
\begin{aligned}
& \Pi_{i}^{f}\left(I_{1}, I_{2}, I_{3}, x\right) \\
& \quad=\left(\mathrm{E}_{\kappa_{i}}\left[\tilde{t}_{i}^{f}\right]-c_{i}\right) x-\mathrm{E}_{\kappa_{i}}\left[\tilde{C}_{i}\left(I_{i}\right)\right] \\
& \quad=\omega_{i}\left(c_{i} x+I_{i}\right),
\end{aligned}
$$

whereas $D_{3}$ shows expected profit

$$
\begin{aligned}
& \Pi_{3}^{f}\left(I_{1}, I_{2}, I_{3}, x\right) \\
&=\left(\mathrm{E}_{\varepsilon}\left[\tilde{p}\left(I_{1}, I_{2}, I_{3}\right)\right]-\sum_{i=1}^{2} \mathrm{E}_{\kappa_{i}}\left[\tilde{t}_{i}^{f}\right]-c_{3}\right) x \\
&-\mathrm{E}_{\kappa_{3}}\left[\tilde{C}_{3}\left(I_{3}\right)\right] \\
&= p\left(I_{1}, I_{2}, I_{3}\right) x \\
&-\left(\sum_{i=1}^{2}\left(1+\omega_{i}\right)\left(c_{i}+\frac{I_{i}}{x}\right)-c_{3}\right) x-I_{3} .
\end{aligned}
$$

All divisions incur a loss amounting to their corresponding expected investment costs $I_{i}$, if no production takes place. Again, the upstream divisions' profits are calculated as transfer payment net of production and investment costs. $D_{3}$ 's profit is defined as turnover net of transfer payments, production, and investment costs.

$D_{3}$ chooses quantity

(10)

$$
\begin{aligned}
& x^{f}\left(I_{1}, I_{2}, I_{3}\right) \\
& = \begin{cases}\bar{x} & \text { if } p(\cdot)-\sum_{i=1}^{2}\left(1+\omega_{i}\right)\left(c_{i}+\frac{I_{i}}{\bar{x}}\right)-c_{3} \geq 0 \\
0 & \text { otherwise }\end{cases}
\end{aligned}
$$

maximizing its expected contribution margin and thereby its expected divisional profit $\Pi_{3}^{f}(\cdot)$. Note that $D_{3}$ bases this decision on an expected contribution margin that does not only account for all variable costs but also for the expected upstream investment costs and a markup on all upstream costs. This means, in turn, that the expected investment costs of the upstream divisions influence the production decision whereas its own investment costs are sunk.

Under the assumption that production takes place, i.e., $x^{f}\left(I_{1}, I_{2}, I_{3}\right)=\bar{x}$, differentiating expected divisional profits with respect to the upstream divisions' investment levels $I_{1}$ and $I_{2}$ yields

$$
\frac{\partial \Pi_{i}^{f}\left(I_{1}, I_{2}, I_{3}, x=\bar{x}\right)}{\partial I_{i}}=\omega_{i} \quad \forall i \in\{1,2\} .
$$

Otherwise no division invests in order to avoid a loss. Note that the derivatives in (11) suggest an overinvestment problem with respect to the upstream divisions as long as the markup factors are positive. Loosely speaking, $D_{1}$ and $D_{2}$ increase their divisional profits by incurring costs. In a more general setting, where the investments would reduce the production costs, it would not be clear that the overinvestment problems of the upstream divisions will occur with transfer prices based on full costs. This would depend on the effect of the investments on the sum of variable and investment costs, which could be positive or negative, resulting in an over- or underinvestment problem.

In the following, we discuss the results of different organizational scenarios. We start with administered transfer prices. Here two scenarios emerge depending on whether inter-divisional negotiations on the investment levels are prohibited or 
permitted. In the third scenario, we modify our assumption of a fully administered transfer-pricing system and allow the upstream divisions to determine both the investment levels and the markup factors in bilateral negotiations.

\subsection{Administered transfer prices without negotiations}

In an administered transfer-pricing system a first alternative for $H Q$ is to choose negative markups. Mathematically, this is a feasible solution, although it appears to be uncommon from a business perspective. With $\omega_{i}<0$ divisions $D_{1}$ and $D_{2}$ renounce to any investment, whereas $D_{3}$ 's investment decision is the same as in the case of transfer prices based on variable costs with small markup factors. A second alternative for $H Q$ are positive markups. At first glance, expression (11) suggests that for positive $\omega_{1}$ and $\omega_{2}$ both $D_{1}$ and $D_{2}$ have an incentive to increase their individual investments unboundedly. However, excessive upstream investments would imply a negative contribution margin for $D_{3}$ due to the corresponding high expected transfer payments, i.e., $p\left(I_{1}, I_{2}, I_{3}\right)-\sum_{i=1}^{2}(1+$ $\left.\omega_{i}\right)\left(c_{i}+I_{i} / \bar{x}\right)-c_{3}<0$, inducing the downstream division to cease production at date $t=4$ according to (10). This implies negative profits for the upstream divisions amounting to their sunk investment costs. Hence, it is not in the upstream divisions' interest to increase their investments to an arbitrarily high level. Rather, it is optimal for each upstream division to raise its investment to the highest level that still induces the downstream division not to cease production. Since both upstream divisions proceed in this manner, maximum investment levels depend on each other. The solution to this problem requires an agreement of the upstream divisions on one combination of investment levels ensuring that $D_{3}$ chooses a positive quantity. In the absence of further coordination it is therefore not obvious which investment levels the upstream divisions should choose. Moreover, infinitely many combinations of upstream investments can just be borne by $D_{3}$.

Note that any solution leaving a positive contribution margin to $D_{3}$ is not self-enforcing. The argument is as follows: Suppose the three divisions agree on investment levels leaving a positive contribution margin for $D_{3}$. In this case each upstream division has an incentive to deviate from the negotiated agreement and to increase its investment beyond the agreed level in order to increase its respective profit, because with full cost-based transfer prices as defined in (7), investment levels and divisional profits are positively related for $D_{1}$ and $D_{2}$. Moreover, the upstream divisions can increase their investment levels and $D_{3}$ - behaving rationally - does not cease production unless its expected contribution margin is negative. But then the upstream divisions end up in a similar situation as before the negotiation: Without any further agreement they do not know how to coordinate investment increases. That is why we restrict our analysis to negotiations between the two upstream divisions leaving a zero expected contribution margin to $D_{3}$.

To formalize this idea, let $I_{1,2}^{f}: \mathbb{R}_{+} \rightarrow 2^{\mathbb{R}_{+}^{2}}$ denote the set of combinations of upstream investments being Pareto efficient with respect to upstream expected divisional profits for given downstream investment $I_{3}$. There are two cases for the parameter setting: On the one hand, it could be that there does not exist any pair of upstream investment levels greater than zero such that $x^{f}\left(I_{1}, I_{2}, I_{3}\right)=\bar{x}$ holds for given $I_{3}$. This is the case, e.g., if the markup factors $\omega_{i}$ are so high that $D_{3}$ 's contribution margin is negative for all positive investment levels. Consequently, the upstream divisions would not invest, i.e., $I_{1,2}^{f}\left(I_{3}\right)=\{(0,0)\}$, and earn zero profits. On the other hand, there could be at least one pair of upstream investment levels such that $D_{3}$ decides to produce. In this case it is neither individually rational for the upstream divisions to choose zero investments nor a combination of investment levels leaving a positive contribution margin to $D_{3}$ since by (8) they increase their own profits by appropriately raising their investment levels. Hence, any $\left(I_{1}, I_{2}\right) \in I_{1,2}^{f}\left(I_{3}\right)$ solves

$$
\begin{aligned}
\left(p\left(I_{1}, I_{2}, I_{3}\right)-\sum_{i=1}^{2}(1\right. & \left.\left.+\omega_{i}\right) c_{i}-c_{3}\right) \bar{x} \\
& -\sum_{i=1}^{2}\left(1+\omega_{i}\right) I_{i}=0 .
\end{aligned}
$$

This condition can be derived from (10) and is equivalent to the fact that $D_{3}$ just earns zero expected contribution margin, if it decides to produce at date $t=4$. Put differently, with $I_{1,2}^{(12)}\left(I_{3}\right) \subset \mathbb{R}_{+}^{2}$ denoting the solutions to (12) in $\left(I_{1}, I_{2}\right)$ we have $I_{1,2}^{f}\left(I_{3}\right) \subseteq I_{1,2}^{(12)}\left(I_{3}\right)$. 
Scrutinizing condition (12), we note that it generally does not single out a unique pair of upstream investments. Refer to the diagram on the left-hand side of Figure 3 for an illustration of $I_{1,2}^{(12)}\left(I_{3}\right)$ for three different pairs $\omega, \omega^{\prime}$, and $\omega^{\prime \prime}$ of positive markup factors $\left(\omega_{1}, \omega_{2}\right)$. The corresponding divisional profits are depicted in the diagram on the right-hand side of Figure 3. Since we know from (8) that upstream divisional profits are increasing in investments, any combination of upstream investments uniquely corresponds to a combination of upstream divisional profits, and vice versa. Thus, both diagrams of Figure 3 can be derived from each other. Moreover, upstream investments belonging to the Pareto boundary of $I_{1,2}^{(12)}\left(I_{3}\right)$, denoted by $\hat{I}_{1,2}^{(12)}\left(I_{3}\right)$, are also Pareto efficient with respect to upstream divisional profits. Pareto boundaries are indicated by bold lines in Figure 3. Hence, the set of upstream investments inducing Pareto-efficient upstream divisional profits, given downstream investment $I_{3}$, is

(13) $I_{1,2}^{f}\left(I_{3}\right)=\left\{\begin{array}{ll}\hat{I}_{1,2}^{(12)}\left(I_{3}\right) & \text { if } \hat{I}_{1,2}^{(12)}\left(I_{3}\right) \neq \emptyset \\ \{(0,0)\} & \text { if } \hat{I}_{1,2}^{(12)}\left(I_{3}\right)=\emptyset\end{array}\right.$.

If $D_{1}$ and $D_{2}$ are able to coordinate their decisions, $I_{1,2}^{f}$ can be interpreted as $D_{1}$ 's and $D_{2}$ 's optimal joint reactions. Interestingly, the Pareto boundary $\hat{I}_{1,2}^{(12)}\left(I_{3}\right)$ may include instances of underinvestment as well as overinvestment, although $D_{1}$ and $D_{2}$ have strong incentives to overinvest expressed by (11). Moreover, underinvestment corresponds to high markup factors, and vice versa. In Figure 3, parameter setting $\omega^{\prime \prime}$ induces upstream investments that are below the first-best levels for both upstream divisions. The key to this observation are the definitions of upstream profits in (8) and (9): High markup factors on upstream production costs imply that even small upstream investments consume $D_{3}$ 's total contribution margin.

To summarize, administered transfer prices do not yield a unique combination of upstream investment levels. Even though it is clear that a selfenforcing solution always entails zero investment of $D_{3}$, the upstream divisions do not know which combination of investment levels they should select from the set of Pareto-efficient investment combinations satisfying (12). Hence, in the considered scenario with administered transfer prices and decentralized operative decision authority, further coordination is necessary.

\subsection{Administered transfer prices with negotiated investments}

In the previous section we have shown that administered transfer prices with positive markup factors provide strong investment incentives for
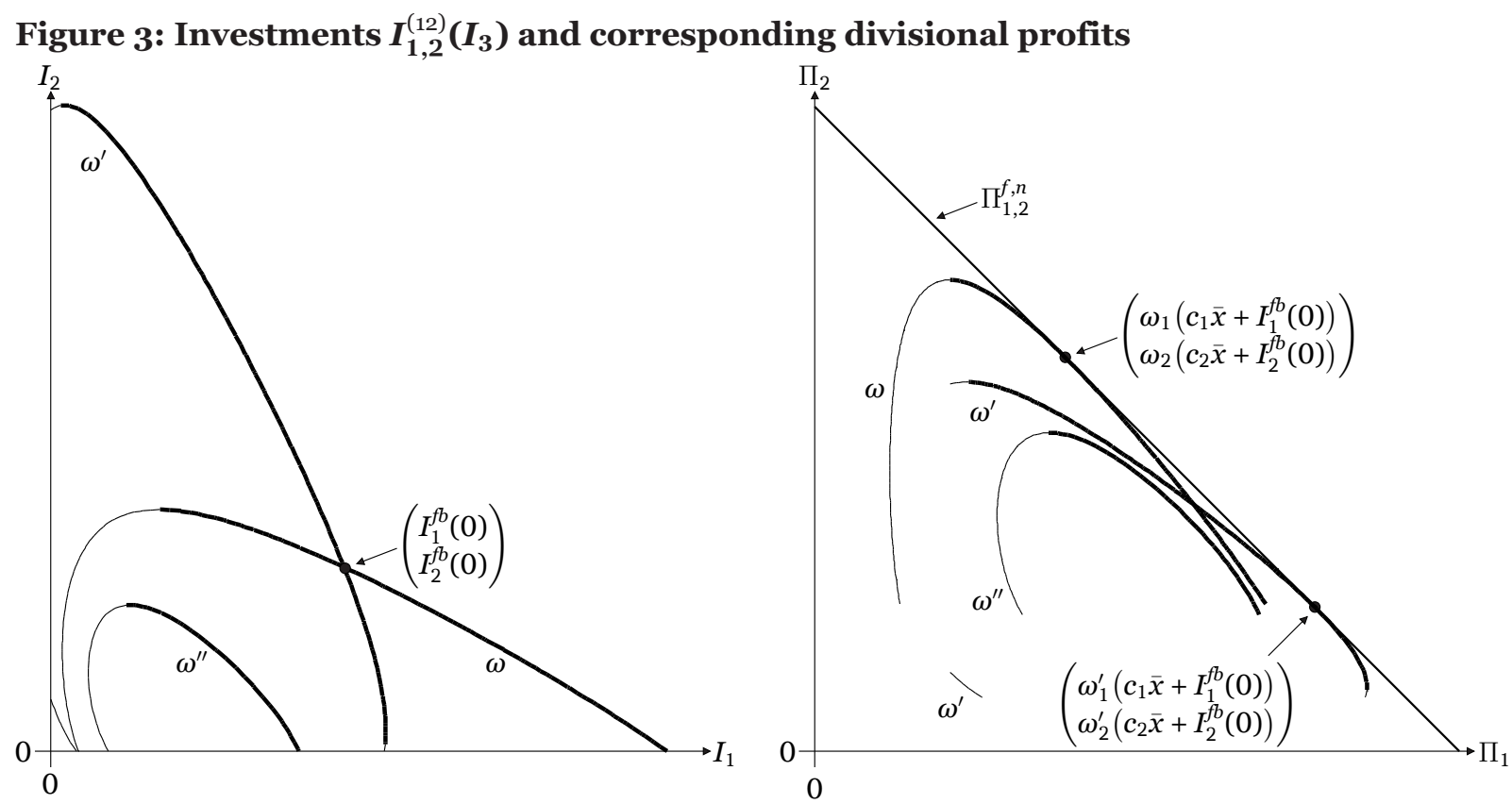

The setting underlying both diagrams is $p\left(I_{1}, I_{2}, I_{3}\right)=\bar{p}-\theta / \prod_{i=1}^{3}\left(a_{i}+I_{i}\right)$ with $\bar{p}=30, \theta=50, a_{1}=a_{3}=1, a_{2}=2, \bar{x}=1$, $c_{1}=c_{2}=c_{3}=1$, and $I_{3}=0$. The values of the markup factors are $\omega \approx(2,4.31), \omega^{\prime} \approx(4,1.57)$, and $\omega^{\prime \prime}=(4,4)$. 
the upstream divisions. However, as both $D_{1}$ and $D_{2}$ want to invest as much as possible such that production is not stopped by $D_{3}$ administered transfer prices are not sufficient to provide adequate coordination among all divisions. In this section, the transfer-pricing system is supplemented with inter-divisional negotiations on the investment levels. Note that the markup factors are still assumed positive and remain under the control of $H Q$. Refer to Appendix C for additional explanations on negotiations under scheme $f$.

The negotiation result is an agreement between the upstream divisions on a pair of investments $\left(I_{1}, I_{2}\right)$ satisfying $I_{1,2}^{f}\left(I_{3}\right)$, i.e., we assume $\left(I_{1}, I_{2}\right) \in I_{1,2}^{f}\left(I_{3}\right)$. In other words, the upstream divisions agree on one joint reaction to given downstream investment $I_{3}$ and thereby solve the coordination problem. Note that such an agreement between $D_{1}$ and $D_{2}$ does not call for a formal contract, because it is in the divisions' interests to stick to the selected equilibrium. Thus, the question to focus on is not enforcement, but coordination. Since any pair of such joint reactions entails zero contribution margin on the downstream production stage, $D_{3}$ never invests in equilibrium and there is no point in the downstream division taking part in the negotiations. This result is stated in the following proposition.

Proposition 3. The equilibrium downstream investment under scheme $f$ with given positive markup factors and negotiated upstream investments is $I_{3}^{f^{*}}=0$.

The main idea of Proposition 3 is that transfer prices based on full costs with positive markups incite the upstream divisions to increase their investments at date $t=3$ extracting all of $D_{3}$ 's contribution margin at date $t=4$. Consequently, $D_{3}$ has no benefit associated to its investment and thus does not invest. Proposition 4 uses this result to derive the equilibrium production decision.

Proposition 4. The equilibrium product quantity under scheme $f$ with given positive markup factors and negotiated upstream investments is

(14) $x^{f^{*}}=\left\{\begin{array}{ll}\bar{x} & \text { if } \hat{I}_{1,2}^{(12)}(0) \neq \emptyset \\ 0 & \text { if } \hat{I}_{1,2}^{(12)}(0)=\emptyset\end{array}\right.$.

The top case of (14) is straightforward because a solution of (12) is equivalent to $D_{3}$ not incurring a loss from production. The bottom case accounts for the case that condition (12) has no solution. On further inspection of this condition, we notice that its solubility depends on the markup factors which are set by $H Q$ : For sufficiently large markup factors revenue does not cover $D_{3}$ 's production costs and the transfer payments, i.e., the left-hand side of (12) is negative. As a consequence, $D_{3}$ ceases production. We get the following existence result concerning the markup factors.

Lemma 1. There exist (sufficiently small) positive markup factors such that $I_{1,2}^{(12)}\left(I_{3}\right) \neq \emptyset$.

The following proposition confirms that it is henceforth justified to restrict attention to sufficiently small markup factors because otherwise $H Q$ would never incur a positive total profit.

Proposition 5. Under scheme $f$ with negotiated upstream investments, (sufficiently large) markup factors such that $I_{1,2}^{f}(0)=\emptyset$ and $I_{3}=0$ are not optimal for $H Q$.

Moreover, total profit is entirely transferred to the upstream divisions leaving $D_{3}$ with zero profit. Formally, with $\left(I_{1}, I_{2}\right) \in I_{1,2}^{f}(0)$ the equilibrium profit allocation exhibits the property $\Pi_{i}^{f}\left(I_{1}, I_{2}, 0, \bar{x}\right)>0$, $i \in\{1,2\}$, and $\Pi_{3}^{f}\left(I_{1}, I_{2}, 0, \bar{x}\right)=0$.

So far, the optimal upstream investments have been conceived as the result of negotiations between $D_{1}$ and $D_{2}$. Anticipating the equilibrium downstream decisions $I_{3}^{f^{*}}=0$ and $x^{f^{*}}=\bar{x}$, this bargaining situation can be described by the set $\Pi_{1,2}^{f, a} \subset \mathbb{R}_{+}^{2}$ defined as

$$
\begin{array}{r}
\Pi_{1,2}^{f, a}=\left\{\left(\Pi_{1}^{f}\left(I_{1}, I_{2}, 0, \bar{x}\right), \Pi_{2}^{f}\left(I_{1}, I_{2}, 0, \bar{x}\right)\right):\right. \\
\left.\left(I_{1}, I_{2}\right) \in I_{1,2}^{f}(0)\right\} .
\end{array}
$$

The set $\Pi_{1,2}^{f, a}$ contains all Pareto-efficient profits the upstream divisions can achieve by their investment decisions. $\Pi_{1,2}^{f, a}$ is indicated by bold lines in the diagram on the right-hand side of Figure 3. It clearly shows that $\Pi_{1,2}^{f, a}$ depends on the markup factors. Let $I_{i}^{f b}: \mathbb{R}_{+} \rightarrow \mathbb{R}_{+}$denote the first-best investment of division $D_{i}, i \in\{1,2\}$, for given $I_{3}$. Analogous to the computation to derive Proposition 1, we get $I_{i}^{f b}(0)>0$. Then, we are able to establish the following benchmark for inter-divisional negotiations. 
Lemma 2. There exist positive markup factors such that $\left(I_{1}^{f b}(0), I_{2}^{f b}(0)\right) \in I_{1,2}^{f}(0)$.

Lemma 2 asserts that $H Q$ may choose markup factors such that - from $H Q$ 's perspective - the most favorable combination of upstream investments $\left(I_{1}^{f b}(0), I_{2}^{f b}(0)\right)$ is a feasible and Pareto-efficient result of the negotiations between $D_{1}$ and $D_{2}$. In Figure 3 this is the case for settings $\omega$ and $\omega^{\prime}$. Yet, generally the divisions only pick this point by chance. Theoretically, the parties could apply a cooperative solution concept which guarantees the agreement on the most favorable combination of upstream investments. In fact, they would come up with this second-best solution if they followed the utilitarian solution, see Myerson (1981), i.e., if they chose a combination of upstream investments that maximizes the sum of their profits which equals total profit. However, if the outcome of the negotiations followed the well-known Nash bargaining solution as introduced in Nash (1950, 1953), the divisions would agree on investments that maximize the product - instead of the sum of divisional profits. Actually, it is not clear whether the upstream divisions want to implement a cooperative solution concept. Generally, they are free to implement any arbitrarily chosen solution, so that the most favorable combination of upstream investments is not guaranteed. Hence, given the bargaining situation in which $H Q$ administers the markup factors, it cannot be taken for granted that the divisions agree on the first-best upstream investments for $I_{3}=0$.

Let us sum up the established results for scheme $f$ with positive markup factors and negotiated investments: First, in a situation with negotiated investment levels, $D_{3}$ is left with zero profit because any other agreement does not form an equilibrium in the investment game and is thus not selfenforcing. Second, it is in $H Q$ 's interest to set small markups because a higher total profit is achieved if production takes place. Third, even if the combination of first-best investment levels, given $I_{3}=0$, is a feasible result of inter-divisional negotiations, the upstream divisions agree upon that solution only by chance. The reason for this is that negotiating the investment levels solely means that both the generation and the allocation of profits are determined in a single step. Thereby, the interests of the division managers are typically not in line with $H Q$ when deciding on divisional investments.
The last point is illustrated in the diagram on the right-hand side of Figure 3 . The bold lines indicate Pareto-efficient profit allocations for $D_{1}$ and $D_{2}$ for given transfer prices. The thin, negatively sloped line indicates feasible divisional profits if both upstream divisions stick to their first-best investment levels and agree upon the profit allocation separately. Delegation of the transfer-pricing authority to $D_{1}$ and $D_{2}$ means to make the thin line feasible. Thus, the upstream divisions can agree upon investments inducing the second-best profit and negotiate the profit allocation in a separate step. This situation is analyzed in the following.

\subsection{Negotiated transfer prices}

We now consider a system of negotiated transfer prices under scheme $f$, i.e., $H Q$ delegates the authority of specifying the markup factors $\omega_{1}$ and $\omega_{2}$ to the upstream divisions. Again, there is no point in $D_{3}$ taking part in the negotiations because, independently of the (positive) markup factors, this division ends up with zero profit for any equilibrium in the investment game, see expression (12) and Proposition 3. The bargaining situation is different now: $D_{1}$ and $D_{2}$ negotiate on both the markup factors and their investment levels at the same time. Let $\Pi_{1,2}^{f, n}$ denote the set of Pareto-efficient upstream profits resulting from this negotiation. Proposition 6 calculates $\Pi_{1,2}^{f, n}$.

Proposition 6. $\Pi_{1,2}^{f, n}$ is given by

$$
\begin{aligned}
\Pi_{1,2}^{f, n}=\{ & \left(\Pi_{1}, \Pi_{2}\right) \in \mathbb{R}_{++}^{2}: \\
& \left.\Pi_{1}+\Pi_{2}=\Pi\left(I_{1}^{f b}(0), I_{2}^{f b}(0), 0, \bar{x}\right)\right\} .
\end{aligned}
$$

The idea of $\Pi_{1,2}^{f, n}$ is that the upstream divisions choose investments that maximize total profit for $I_{3}=0$ and shift this profit by means of the markup factors arbitrarily between each other. Consult the diagram on the right-hand side of Figure 3 for an illustration of $\Pi_{1,2}^{f, n}$. $\Pi_{1,2}^{f, n}$ may be interpreted as the envelope of all profit combinations that arise if positive markup factors are chosen such that firstbest investments $\left(I_{1}^{f b}(0), I_{2}^{f b}(0)\right)$ are a solution of condition (12).

It is important that it does not matter to $H Q$ in this bargaining situation on which profit combination the upstream divisions actually agree since any combination in $\Pi_{1,2}^{f, n}$ yields the same (maximal) total profit. Thus, there is no dependency of aggre- 
gate efficiency on the special negotiation outcome. Furthermore, a comparison of the two bargaining situations suggests a remarkable conclusion: It is possible to overcome dysfunctional incentives rooted in responsibility-center organization by actually reducing the degree of central planning in the form of delegating the transfer-pricing authority.

\section{Conclusions and managerial implications}

Transfer prices are a prominent instrument of coordination in decentralized firms. This paper focuses on the performance of simple cost-based transfer-pricing schemes, which are prevailing in business practice as to the coordination of investment and production decisions in a decentralized setting of team production for inducing qualityimproving investments. In addition to the teamproduction setting, we allow for two divisions on the upstream production stage. The convergent production structure is the driving force of the identified coordination problems.

In a first step, we concentrate on the hypothetical first-best situation where central management takes and enforces all decisions in an optimal way. The second step is the analysis of the performance of different transfer-pricing schemes applied in the corresponding second-best situation.

Transfer prices based on variable costs are able to induce coordination, but the upstream divisions have no incentive to invest and the downstream division maximizes total profit given the underinvestment of the upstream divisions. Accordingly, additional organizational instruments, such as investment committees or mandatory minimal investment levels, are indicated.

In contrast to the variable cost-based scheme, transfer prices based on full costs offer strong incentives for overinvestment on the upstream production stage under administered transfer prices with positive markups. Moreover, like in the variable cost-based scheme with high markups, the existence of two divisions on the same production stage overcharges the coordination capability of the transfer price. From an organizational perspective, investment budgets may mitigate this problem but entail new agency problems. Another solution approach is to choose negative markups implying that the upstream divisions restrain from any investment activities. With respect to divisional investments and total profit, this solution is identical to the scheme based on variable costs with small markups. Therefore, a change of the organizational arrangements seems promising. Allowing for negotiations between the upstream division managers on the investment levels yields a solution to the overinvestment and coordination problem. Nevertheless, first-best upstream investments can only be guaranteed if negotiations include both the investments and the markup factors. Thus, the delegation of transfer-pricing authority may be a viable option for $H Q$ in order to improve coordination. Even though this paper concentrates on quality-improving investments, there is probably also potential to benefit from negotiations in situations where investments bear on production costs. Comparing the different schemes for motivating quality-improving investments, it holds true that negotiations on transfer prices based on full costs always guarantee at least a total profit as high as administered transfer prices based on full costs with positive markups and negotiated investment levels. Other dominance relations depend on the actual parameter setting. The strength of transfer prices based on variable costs is the investment incentive on the downstream production stage. The opposite is true for full cost-based transfer pricing. Consequently, the former is the better choice if the investments of the downstream division are critical for the product's quality compared to the downstream investments, and vice versa.

\section{Appendix A: Proofs}

\section{A.1 Proof of Proposition 1}

The contribution margin which can be improved by divisional investments is assumed to be positive, such that the maximal product quantity is optimal. The objective function is assumed to be strictly concave in the investment levels. The firstorder derivatives of the expected total profit with respect to a single divisional investment level $I_{i}$, $i \in\{1,2,3\}$, are assumed to be strictly positive which yields the positive first-best investments $I_{i}^{f b^{*}}>0, i \in\{1,2,3\}$. 


\section{A.2 Proof of Proposition 2}

Inspecting (6) we conclude that

$$
p\left(I_{1}, I_{2}, I_{3}\right)-\sum_{i=1}^{2}\left(1+\gamma_{i}\right) c_{i}-c_{3} \geq 0
$$

holds for any combination of (non-negative) investments and thus $x=\bar{x}$ is an optimal quantity decision for $D_{3}$ independent of the divisional investments. As production is guaranteed by (17), any positive investment on the upstream production stage decreases the upstream divisions' profits given by (4) so that $I_{1}=I_{2}=0$ holds in equilibrium. $D_{3}$ 's individual profit maximization for $x=\bar{x}$ is characterized by

$$
\frac{\partial \Pi_{3}^{v}(0,0,0, \bar{x})}{\partial I_{3}}>0
$$

such that choosing a strictly positive investment level is optimal for $D_{3}$.

\section{A.3 Proof of Proposition 3}

$D_{3}$ 's objective function for deriving the optimal level of its investment can be inferred from (9): It is $\Pi_{3}^{f}\left(I_{1}, I_{2}, I_{3}, x^{f}\left(I_{1}, I_{2}, I_{3}\right)\right)$. Let $I_{3}^{f}\left(I_{1}, I_{2}\right)$ denote the optimal downstream investment in reaction to upstream investments $\left(I_{1}, I_{2}\right) \in \mathbb{R}_{+}^{2}$. Then, it is sufficient to show that $I_{3}^{f}\left(I_{1}, I_{2}\right)=0$ holds for $\left(I_{1}, I_{2}\right) \in I_{1,2}^{f}\left(I_{3}\right)$.

Start with the assumption $I_{3}^{f}\left(I_{1}, I_{2}\right)>0$. Suppose first that $x^{f}\left(I_{1}, I_{2}, I_{3}^{f}\left(I_{1}, I_{2}\right)\right)=0$. Then, $D_{3}$ 's loss amounts to its investment costs and $I_{3}^{f}\left(I_{1}, I_{2}\right)>0$ cannot be optimal since $I_{3}^{f}\left(I_{1}, I_{2}\right)=0$ implies zero profit for $D_{3}$. Now suppose that $x^{f}\left(I_{1}, I_{2}, I_{3}^{f}\left(I_{1}, I_{2}\right)\right)=\bar{x}$. Since $\left(I_{1}, I_{2}\right) \in I_{1,2}^{f}\left(I_{3}\right)$ holds in equilibrium, condition (12) applies and $D_{3}$ again incurs a loss for every positive investment level. Consequently, $I_{3}^{f}\left(I_{1}, I_{2}\right)=0$ holds for $\left(I_{1}, I_{2}\right) \in I_{1,2}^{f}\left(I_{3}\right)$.

\section{A.4 Proof of Proposition 4}

The assertion uses Proposition 3 and follows from (10) and (13). For $\hat{I}_{1,2}^{(12)}(0) \neq \emptyset$, we have $\left(I_{1}, I_{2}\right) \in I_{1,2}^{f}(0)=\hat{I}_{1,2}^{(12)}(0)$. Thus, condition (12) is satisfied and thereby

$x^{f}\left(I_{1}, I_{2}, 0\right)=\bar{x}$ holds for any $\left(I_{1}, I_{2}\right) \in I_{1,2}^{f}(0)$. Otherwise the upstream divisions do not invest according to (13) and $p(0,0,0)-\sum_{i=1}^{2}\left(1+\omega_{i}\right) c_{i}-c_{3}<0$ holds. Referring to (10), this implies $x^{f}(0,0,0)=0$ which completes the proof.

\section{A.5 Proof of Lemma 1}

$p\left(I_{1}, I_{2}, I_{3}\right)-\sum_{i=1}^{3} c_{i}>0$ follows from the assumption $\Pi(0,0,0, x)>0$ for $x>0$. Consequently, the left-hand side of (12) is positive for $I_{1}=I_{2}=0$ and sufficiently small markup factors $\omega_{i}$. As the price function $p$ is increasing and bounded in $I_{i}$, $i \in\{1,2,3\}$, by the intermediate-value theorem there always exists a pair of upstream investments $\left(I_{1}, I_{2}\right) \neq 0$ satisfying (12) for any given $I_{3}$.

\section{A.6 Proof of Proposition 5}

Lemma 1 ensures existence of markup factors $\omega_{i}>0, i \in\{1,2\}$, such that $I_{1,2}^{f}(0) \neq \emptyset$. Suppose such markup factors are chosen. Then, by (13) and Propositions 3 and 4, we have positive total profit $\Pi\left(I_{1}, I_{2}, 0, \bar{x}\right)>0$. Otherwise, total profit is zero according to $\Pi(0,0,0,0)=0$.

\section{A.7 Proof of Lemma 2}

As $I_{i}^{f b}(0)>0, i \in\{1,2\}$, the markup factors necessarily are such that $I_{1,2}^{f}(0)=\hat{I}_{1,2}^{(12)}(0)$. Accordingly, we have to verify that there are markup factors such that $\left(I_{1}^{f b}(0), I_{2}^{f b}(0)\right) \in \hat{I}_{1,2}^{(12)}(0)$. First, we check that $\left(I_{1}^{f b}(0), I_{2}^{f b}(0)\right) \in I_{1,2}^{(12)}(0)$. Evaluating the left-hand side of (12) for $\left(I_{1}^{f b}(0), I_{2}^{f b}(0)\right)$ yields

$$
\begin{aligned}
\left(p\left(I_{1}^{f b}(0), I_{1}^{f b}(0), 0\right)\right. & \left.-\sum_{i=1}^{2}\left(1+\omega_{i}\right) c_{i}-c_{3}\right) \bar{x} \\
& -\sum_{i=1}^{2}\left(1+\omega_{i}\right) I_{i}^{f b}(0) .
\end{aligned}
$$

Obviously, for sufficiently large markup factors (19) is negative. For $\omega_{1}=\omega_{2}=0$ (19) equals $\Pi\left(I_{1}^{f b}(0), I_{2}^{f b}(0), 0, \bar{x}\right)$ which is positive. Hence, by the intermediate-value theorem there must be markup factors $\omega_{1}, \omega_{2}>0$ such that condition (12) holds for $\left(I_{1}^{f b}(0), I_{2}^{f b}(0)\right)$.

Pareto efficiency of $\left(I_{1}^{f b}(0), I_{2}^{f b}(0)\right)$ follows from the fact that $\Pi\left(I_{1}^{f b}(0), I_{2}^{f b}(0), 0, \bar{x}\right)$ is maximal for $I_{3}=0$ and thus the corresponding profit allocation

(20) $\quad\left(\Pi_{1}^{f}\left(\left(I_{1}^{f b}(0), I_{2}^{f b}(0), 0, \bar{x}\right)\right.\right.$,

$$
\left.\Pi_{2}^{f}\left(I_{1}^{f b}(0), I_{2}^{f b}(0), 0, \bar{x}\right)\right)
$$

is Pareto efficient.

\section{A.8 Proof of Proposition 6}

First note that the profit combinations in (16) are Pareto efficient since the upstream investments are 
first best given $I_{3}=0$. We then have to verify that for each profit combination in (16) there is a pair of markup factors described by Lemma 2 that induces it. Let $\Omega \subset \mathbb{R}_{++}^{2}$ denote the set of pairs of markup factors described by Lemma 2. We conclude $\Omega=$ $\left\{\left(\omega_{1}, \omega_{2}\right) \in \mathbb{R}_{++}^{2}: \omega_{2}=a-b \omega_{1}\right\}$ from (19), where $a$ and $b$ are positive constants. Note that $\Omega$ defines a negatively sloped line in $\mathbb{R}_{++}^{2}$. For each pair of markup factors $\left(\omega_{1}, \omega_{2}\right) \in \Omega$ we have upstream divisional profits $\Pi_{i}^{f}\left(I_{1}^{f b}(0), I_{2}^{f b}(0), 0, \bar{x}\right)=\omega_{i}\left(c_{i} \bar{x}+\right.$ $\left.I_{i}^{f b}(0)\right), i \in\{1,2\}$, which sum up to the maximal value $\Pi\left(I_{1}^{f b}(0), I_{2}^{f b}(0), 0, \bar{x}\right)$. These profit functions are positive linear transformations of the markup factors. Hence, $\left(\omega_{1}\left(c_{1} \bar{x}+I_{1}^{f b}(0)\right), \omega_{2}\left(c_{2} \bar{x}+I_{2}^{f b}(0)\right)\right)$ is a parametrization of $\Pi_{1,2}^{f, n}$.

\section{Appendix B: Example}

To illustrate the general analysis developed in the paper, this appendix presents analytical and numerical results for a specific price function. Here the interrelated effects of the decentralized investments are reflected by the sales price $\tilde{p}$ which reciprocally depends on multiplicatively connected investment levels. We have

(21) $\tilde{p}\left(I_{1}, I_{2}, I_{3}\right)=\bar{p}-\frac{\theta}{\prod_{i=1}^{3}\left(a_{i}+I_{i}\right)}+\varepsilon$

with investment level $I_{i} \geq 0$ and costs $\tilde{C}_{i}\left(I_{i}\right)=$ $I_{i}+\kappa_{i} \geq 0, i \in\{1,2,3\}, a_{i}>0$ symbolizing the capital stock of $D_{i}$ already in place, and constant $\theta>0$ calibrating the investment effect. $\varepsilon$ and $\kappa_{i}$ are independent random variables with mean $\mu(\varepsilon)=\mu\left(\kappa_{i}\right)=0$. The expected sales price and investment costs are given by

$$
\begin{aligned}
& E_{\varepsilon}\left[\tilde{p}\left(I_{1}, I_{2}, I_{3}\right)\right] \\
& =\bar{p}-\frac{\theta}{\prod_{i=1}^{3}\left(a_{i}+I_{i}\right)}=: p\left(I_{1}, I_{2}, I_{3}\right)>0
\end{aligned}
$$

and

$$
E_{\kappa_{i}}\left[\tilde{C}_{i}\left(I_{i}\right)\right]=I_{i}=: C_{i} \geq 0 \quad \forall i \in\{1,2,3\} .
$$

Even with arbitrarily large investments in all divisions the supremum $\bar{p}>0$ of the sales price cannot be reached, as the marginal investment effect decreases with increasing investment levels as depicted in Figure 4.
Figure 4: Price function

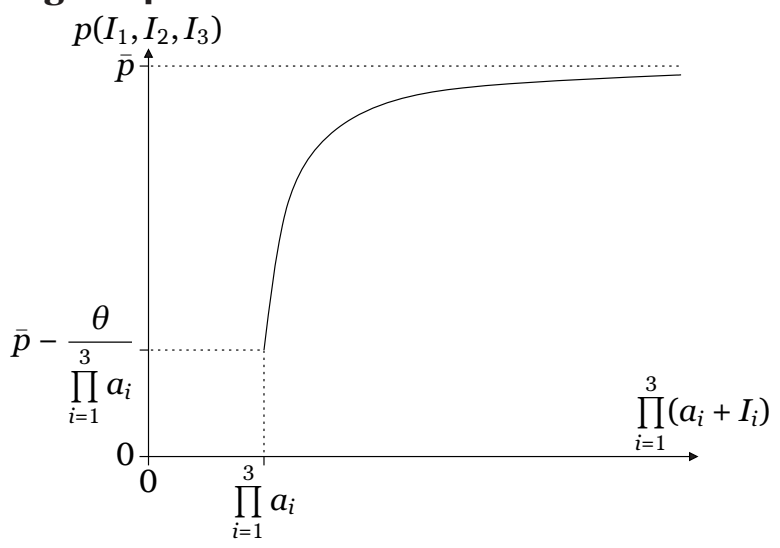

Under the assumption $(\theta \bar{x})^{1 / 4}>\max \left\{a_{1}, a_{2}, a_{3}\right\}$, the first-best investment policy entails positive investment levels in all divisions.

\section{B.1 First-best situation}

The first-best investment levels $I_{i}^{f b^{*}}, i \in\{1,2,3\}$, are given by

(24) $I_{i}^{f b^{*}}=(\theta \bar{x})^{1 / 4}-a_{i}>0$.

Further, the optimal investment levels decrease in initial endowments $a_{i}$. The optimal solution is characterized by $\left(a_{i}+I_{i}\right)=\left(a_{j}+I_{j}\right) \forall i, j$, which reflects the decisions' interdependence. With the investment levels according to (24), the maximum total profit is given by

$$
\begin{aligned}
& \Pi\left(I_{1}^{f b^{*}}, I_{2}^{f b^{*}}, I_{3}^{f b^{*}}, \bar{x}\right) \\
& \quad=\left(\bar{p}-\sum_{i=1}^{3} c_{i}\right) \bar{x}-4(\theta \bar{x})^{1 / 4}+\sum_{i=1}^{3} a_{i} .
\end{aligned}
$$

This profit serves as a benchmark measuring organizational efficiency when we take the informational asymmetry into consideration.

\section{B.2 Transfer prices based on variable costs}

With transfer prices based on variable costs and sufficiently small markup factors $\gamma_{1}$ and $\gamma_{2}$, see Proposition 2, the divisional investments in equilibrium are given by $I_{1}^{v^{*}}=I_{2}^{v^{*}}=0$ and

$$
I_{3}^{v^{*}}=\sqrt{\frac{\theta \bar{x}}{a_{1} a_{2}}}-a_{3}>0
$$


Interestingly, the level of $I_{3}^{v^{*}}$ is independent of the specific combinations of markups satisfying condition (6). This is due to the absence of any quantity effects in the price function (1). Observe that the optimality condition for $D_{3}$ 's investment is the same as in the first-best situation. However, the actual investment level is not first best since $D_{1}$ and $D_{2}$ do not behave accordingly but renounce to any investments. Summing up, for transfer prices based on variable costs with small markup factors the optimal investment levels and profits emerge as given in Table 1.

\section{B.3 Transfer prices based on full costs}

With transfer prices based on full costs, the markup factors are $\omega_{1}$ and $\omega_{2}$. Under the assumption that production takes place, i.e., $x^{f}\left(I_{1}, I_{2}, I_{3}\right)=\bar{x}$, deriv- ing divisional profits with respect to the divisions' investment levels yields

(27)

$$
\begin{aligned}
& \frac{\partial \Pi_{i}^{f}\left(I_{1}, I_{2}, I_{3}, x=\bar{x}\right)}{\partial I_{i}} \\
& =\left\{\begin{array}{ll}
\omega_{i} & \text { if } i \in\{1,2\} \\
\frac{\theta \bar{x}}{\left(a_{3}+I_{3}\right) \prod_{j=1}^{3}\left(a_{j}+I_{j}\right)} & \text { if } i=3
\end{array} .\right.
\end{aligned}
$$

Consider the case with administered prices without negotiations. HQ can choose negative markups, which yields the same optimal investment levels and total profit as under scheme $v$ which can be inferred from comparing Table 2 with Table 1 . Table 3 summarizes the results for negotiated scheme $f$.

Table 1: Investments and profits for scheme $v$

\begin{tabular}{ccc}
\hline Division $D_{i}$ & Investment $I_{i}^{v^{*}}$ & Profit $\Pi_{i}^{v}\left(I_{1}^{v^{*}}, I_{2}^{v^{*}}, I_{3}^{v^{*}}, \bar{x}\right)$ \\
\hline$D_{1}$ & 0 & $\gamma_{1} c_{1} \bar{x}$ \\
\hline$D_{2}$ & 0 & $\gamma_{2} c_{2} \bar{x}$ \\
\hline$D_{3}$ & $\sqrt{\frac{\theta \bar{x}}{a_{1} a_{2}}}-a_{3}$ & $\left(\bar{p}-\sum_{i=1}^{2}\left(1+\gamma_{i}\right) c_{i}-c_{3}\right) \bar{x}-2 \sqrt{\frac{\theta \bar{x}}{a_{1} a_{2}}}+a_{3}$ \\
\hline \multirow{2}{*}{ Total profit } & $\sum_{i=1}^{3} \Pi_{i}^{v}(\cdot)=\left(\bar{p}-\sum_{i=1}^{3} c_{i}\right) \bar{x}-2 \sqrt{\frac{\theta \bar{x}}{a_{1} a_{2}}}+a_{3}$ \\
\hline
\end{tabular}

Table 2: Investments and profits for administered scheme $\boldsymbol{f}$ (negative markups)

\begin{tabular}{ccc}
\hline Division $D_{i}$ & Investment $I_{i}^{f^{*}}$ & $\operatorname{Profit} \Pi_{i}^{f}\left(f_{1}^{f^{*}}, I_{2}^{f^{*}}, I_{3}^{f^{*}}, \bar{x}\right)$ \\
\hline$D_{1}$ & 0 & $\omega_{1} c_{1} \bar{x}$ \\
\hline$D_{2}$ & 0 & $\omega_{2} c_{2} \bar{x}$ \\
\hline$D_{3}$ & $\sqrt{\frac{\theta \bar{x}}{a_{1} a_{2}}}-a_{3}$ & $\left(\bar{p}-\sum_{i=1}^{2}\left(1+\omega_{i}\right)\left(c_{i}+\frac{I_{i}}{\bar{x}}\right)-c_{3}\right) \bar{x}-2 \sqrt{\frac{\theta \bar{x}}{a_{1} a_{2}}}+a_{3}$ \\
\hline \multirow{2}{*}{ Total profit } & \multicolumn{2}{c}{$\sum_{i=1}^{3} \Pi_{i}^{f}(\cdot)=\left(\bar{p}-\sum_{i=1}^{3} c_{i}\right) \bar{x}-2 \sqrt{\frac{\theta \bar{x}}{a_{1} a_{2}}}+a_{3}$} \\
\hline
\end{tabular}

Table 3: Investments and profits for negotiated scheme $f$

\begin{tabular}{ccc}
\hline Division $D_{i}$ & Investment $f_{i}^{f^{*}}$ & Profit $\Pi_{i}^{f}\left(I_{1}^{f^{*}}, f_{2}^{f^{*}}, I_{3}^{f^{*}}, \bar{x}\right)$ \\
\hline$D_{1}$ & $\left(\frac{\theta \bar{x}}{a_{3}}\right)^{1 / 3}-a_{1}$ & $\omega_{1}\left(c_{1} \bar{x}+\left(\frac{\theta \bar{x}}{a_{3}}\right)^{1 / 3}-a_{1}\right)$ \\
\hline$D_{2}$ & $\left(\frac{\theta \bar{x}}{a_{3}}\right)^{1 / 3}-a_{2}$ & $\omega_{2}\left(c_{2} \bar{x}+\left(\frac{\theta \bar{x}}{a_{3}}\right)^{1 / 3}-a_{2}\right)$ \\
\hline$D_{3}$ & 0 & 0 \\
\hline Total profit & $\sum_{i=1}^{3} \Pi_{i}^{f}(\cdot)=\left(\bar{p}-\sum_{i=1}^{3} c_{i}\right) \bar{x}-3\left(\frac{\theta \bar{x}}{a_{3}}\right)^{1 / 3}+a_{1}+a_{2}$ \\
\hline
\end{tabular}




\section{B.4 Numerical results}

In the following, we calculate the profits for different parameter settings. The upper bound of the sales price is given by $\bar{p}=30$, the scaling parameter $\theta$ is set to 50 , the variable production costs of the divisions are $c_{1}=c_{2}=c_{3}=1$ and the (maximum) sales quantity is $\bar{x}=3$. The capital-stock endowment of division 3 is $a_{3}=2.5$, whereas $a_{1}$ and $a_{2}$ can be inferred from the column and row headings in the tables. All numbers are rounded to two digits after the decimal point.

We give a reading example for Table 4 showing the model results for the first-best case: Consider the entries for $a_{1}=a_{2}=1$. Here, the investment levels of $D_{1}$ and $D_{2}$ are $I_{1}^{f b}=I_{1}^{f b} \approx 2.50$, whereas $D_{3}$ only invests $I_{3}^{f b} \approx 1.00$. Divisional profits are not defined for the first-best case. Total profit is given by $\Pi\left(I_{1}^{f b}, I_{2}^{f b}, I_{3}^{f b}, \bar{x}\right) \approx 71.50$. Obviously, in the optimum capital stocks after investments are equal in all divisions, meaning the marginal rates of capital productivity are equal over the three divisions ex post. Consequently, total profits only differ due to varying investment costs.

In Table 5 the results are presented for transfer prices based on variable costs (scheme $v$ ) with small markups. In addition to the parameters mentioned above, the markups $\gamma_{1}=\gamma_{2}=0.1$ are introduced. As stated in the paper, $D_{1}$ and $D_{2}$ cannot

\section{Table 4: Numerical example for the}

\section{first-best case}

\begin{tabular}{crrrrr}
\hline & \multicolumn{5}{c}{$a_{1}$} \\
\cline { 2 - 5 } & 1.0 & 1.5 & 2.0 & 2.5 & $a_{2}$ \\
\hline$I_{1}^{f b}$ & 2.50 & 2.00 & 1.50 & 1.00 & \\
$I_{2}^{f b}$ & 2.50 & 2.50 & 2.50 & 2.50 & \\
$I_{3}^{f b}$ & 1.00 & 1.00 & 1.00 & 1.00 & 1.0 \\
$\Pi\left(I_{1}^{f b}, I_{2}^{f b}, I_{3}^{f b}, \bar{x}\right)$ & 71.50 & 72.00 & 72.50 & 73.00 & \\
\hline$I_{1}^{f b}$ & 2.50 & 2.00 & 1.50 & 1.00 & \\
$I_{2}^{f b}$ & 2.00 & 2.00 & 2.00 & 2.00 & \\
$I_{3}^{f b}$ & 1.00 & 1.00 & 1.00 & 1.00 & 1.5 \\
$\Pi\left(I_{1}^{f b}, I_{2}^{f b}, I_{3}^{f b}, \bar{x}\right)$ & 72.00 & 72.50 & 73.00 & 73.50 & \\
\hline$I_{1}^{f b}$ & 2.50 & 2.00 & 1.50 & 1.00 & \\
$I_{2}^{f b}$ & 1.50 & 1.50 & 1.50 & 1.50 & \\
$I_{3}^{f b}$ & 1.00 & 1.00 & 1.00 & 1.00 & 2.0 \\
$\Pi\left(I_{1}^{f b}, I_{2}^{f b}, I_{3}^{f b}, \bar{x}\right)$ & 72.50 & 73.00 & 73.50 & 74.00 & \\
\hline$I_{1}^{f b}$ & 2.50 & 2.00 & 1.50 & 1.00 & \\
$I_{2}^{f b}$ & 1.00 & 1.00 & 1.00 & 1.00 & \\
$I_{3}^{f b}$ & 1.00 & 1.00 & 1.00 & 1.00 & 2.5 \\
$\Pi\left(I_{1}^{f b}, I_{2}^{f b}, I_{3}^{f b}, \bar{x}\right)$ & 73.00 & 73.50 & 74.00 & 74.50 & \\
\hline
\end{tabular}

Table 5: Numerical example for scheme $v$

\begin{tabular}{|c|c|c|c|c|c|}
\hline & \multicolumn{4}{|c|}{$a_{1}$} & \multirow[b]{2}{*}{$a_{2}$} \\
\hline & 1.0 & 1.5 & 2.0 & 2.5 & \\
\hline$I_{1}^{v^{*}}$ & 0 & 0 & 0 & 0 & \\
\hline$I_{2}^{v^{*}}$ & 0 & 0 & 0 & 0 & \\
\hline$I_{3}^{v^{*}}$ & 9.75 & 7.50 & 6.16 & 5.25 & \\
\hline$\Pi_{1}^{v}\left(I_{1}^{v^{*}}, I_{2}^{v^{*}}, I_{3}^{v^{*}}, \bar{x}\right)$ & 0.30 & 0.30 & 0.30 & 0.30 & 1.0 \\
\hline$\Pi_{2}^{v}\left(I_{1}^{v^{*}}, I_{2}^{v^{*}}, I_{3}^{v^{*}}, \bar{x}\right)$ & 0.30 & 0.30 & 0.30 & 0.30 & \\
\hline$\Pi_{3}^{v}\left(I_{1}^{v^{*}}, I_{2}^{v^{*}}, I_{3}^{v^{*}}, \bar{x}\right)$ & 58.41 & 62.90 & 65.58 & 67.41 & \\
\hline$\Pi\left(I_{1}^{v^{*}}, I_{2}^{v^{*}}, I_{3}^{v^{*}}, \bar{x}\right)$ & 59.01 & 63.50 & 66.18 & 68.01 & \\
\hline$I_{1}^{v^{*}}$ & 0 & 0 & 0 & 0 & \\
\hline$I_{2}^{v^{*}}$ & 0 & 0 & 0 & 0 & \\
\hline$I_{3}^{v^{*}}$ & 7.50 & 5.66 & 4.57 & 3.82 & \\
\hline$\Pi_{1}^{v}\left(I_{1}^{v^{*}}, I_{2}^{v^{*}}, I_{3}^{v^{*}}, \bar{x}\right)$ & 0.30 & 0.30 & 0.30 & 0.30 & 1.5 \\
\hline$\Pi_{2}^{v}\left(I_{1}^{v^{*}}, I_{2}^{v^{*}}, I_{3}^{v^{*}}, \bar{x}\right)$ & 0.30 & 0.30 & 0.30 & 0.30 & \\
\hline$\Pi_{3}^{v}\left(I_{1}^{v^{*}}, I_{2}^{v^{*}}, I_{3}^{v^{*}}, \bar{x}\right)$ & 62.90 & 66.57 & 68.76 & 70.25 & \\
\hline$\Pi\left(I_{1}^{v^{*}}, I_{2}^{v^{*}}, I_{3}^{v^{*}}, \bar{x}\right)$ & 63.50 & 67.17 & 69.36 & 70.85 & \\
\hline$I_{1}^{v^{*}}$ & 0 & 0 & 0 & 0 & \\
\hline$I_{2}^{v^{*}}$ & 0 & 0 & 0 & 0 & \\
\hline$I_{3}^{v^{*}}$ & 6.16 & 4.57 & 3.62 & 2.98 & \\
\hline$\Pi_{1}^{v}\left(I_{1}^{v^{*}}, I_{2}^{v^{*}}, I_{3}^{v^{*}}, \bar{x}\right)$ & 0.30 & 0.30 & 0.30 & 0.30 & 2.0 \\
\hline$\Pi_{2}^{v}\left(I_{1}^{v^{*}}, I_{2}^{v^{*}}, I_{3}^{v^{*}}, \bar{x}\right)$ & 0.30 & 0.30 & 0.30 & 0.30 & \\
\hline$\Pi_{3}^{v}\left(I_{1}^{v^{*}}, I_{2}^{v^{*}}, I_{3}^{v^{*}}, \bar{x}\right)$ & 65.58 & 68.76 & 70.65 & 71.95 & \\
\hline$\Pi\left(I_{1}^{v^{*}}, I_{2}^{v^{*}}, I_{3}^{v^{*}}, \bar{x}\right)$ & 66.18 & 69.36 & 71.25 & 72.55 & \\
\hline$I_{1}^{v^{*}}$ & 0 & 0 & 0 & 0 & \\
\hline$I_{2}^{v^{*}}$ & 0 & 0 & 0 & 0 & \\
\hline$I_{3}^{v^{*}}$ & 5.25 & 3.82 & 2.98 & 2.40 & \\
\hline$\Pi_{1}^{v}\left(I_{1}^{v^{*}}, I_{2}^{v^{*}}, I_{3}^{v^{*}}, \bar{x}\right)$ & 0.30 & 0.30 & 0.30 & 0.30 & 2.5 \\
\hline$\Pi_{2}^{v}\left(I_{1}^{v^{*}}, I_{2}^{v^{*}}, I_{3}^{v^{*}}, \bar{x}\right)$ & 0.30 & 0.30 & 0.30 & 0.30 & \\
\hline$\Pi_{3}^{v}\left(I_{1}^{v^{*}}, I_{2}^{v^{*}}, I_{3}^{v^{*}}, \bar{x}\right)$ & 67.41 & 70.25 & 71.95 & 73.10 & \\
\hline$\Pi\left(I_{1}^{v^{*}}, I_{2}^{v^{*}}, I_{3}^{v^{*}}, \bar{x}\right)$ & 68.01 & 70.85 & 72.55 & 73.70 & \\
\hline
\end{tabular}

be motivated to invest. Further - as no quantity effects occur - divisional profits of $D_{1}$ and $D_{2}$ remain stable over all combinations of capital stocks. In contrast, $D_{3}$ invests less the higher the other divisions' capital stocks are, thereby raising its own profit.

Table 6 exhibits the results for administered transfer prices based on full costs (scheme $f$ ) without negotiations over the investment levels. Here the parameters $\omega_{1}=\omega_{2}=-0.1$ are introduced. Note that they are negative in order to prevent the coordination problem explained in the paper. Since $D_{1}$ and $D_{2}$ still cannot be motivated to invest, total profits remain unchanged compared to Table 5 . However, due to differing transfer prices the allocation of total profit among the divisions alters.

Table 7 provides the results for negotiated transfer prices based on full costs. Note that in comparison to scheme $f$ with negative markups inverse invest- 
ment incentives are induced, i.e., the upstream divisions are motivated to invest whereas $D_{3}$ restrains from investment. As shown in the paper, $D_{1}$ 's and $D_{2}$ 's decisions leave $D_{3}$ with zero profit. Furthermore, uncountably many pairs $\left(\omega_{1}, \omega_{2}\right)$ exist which generate the presented investments. By setting $\omega_{1}=7$ and adjusting $\omega_{2}$ appropriately we arbitrarily choose one of them. The notably high markup factors are due to the parameter setting.

Table 6: Numerical example for administered scheme $f$ (negative markups)

\begin{tabular}{|c|c|c|c|c|c|}
\hline & \multicolumn{4}{|c|}{$a_{1}$} & \multirow[b]{2}{*}{$a_{2}$} \\
\hline & 1.0 & 1.5 & 2.0 & 2.5 & \\
\hline-1 & 0 & 0 & 0 & 0 & \\
\hline$I_{2}^{f^{*}}$ & 0 & 0 & 0 & 0 & \\
\hline$f^{*}$ & 9.75 & 7.50 & 6.16 & 5.25 & \\
\hline$\Pi_{1}^{f}\left(I_{1}^{f^{*}}, I_{2}^{f^{*}}, I_{3}^{f^{*},}, \bar{x}\right)$ & -0.30 & -0.30 & -0.30 & -0.30 & 1.0 \\
\hline$\Pi_{2}^{f}\left(I_{1}^{f^{*}}, \bar{f}_{2}^{f^{*}}, I_{3}^{f^{*}}, \bar{x}\right)$ & -0.30 & -0.30 & -0.30 & -0.30 & \\
\hline$\Pi_{3}^{f}\left(I_{1}^{f^{*}}, f_{2}^{f^{*}}, I_{3}^{f^{*}}, \bar{x}\right)$ & 59.61 & 64.10 & 66.78 & 68.61 & \\
\hline$\Pi\left(I_{1}^{f^{*}}, I_{2}^{f^{*}}, I_{3}^{f^{*}}, \bar{x}\right)$ & 59.01 & 63.50 & 66.18 & 68.01 & \\
\hline$f^{*}$ & 0 & 0 & 0 & 0 & \\
\hline & 0 & 0 & 0 & 0 & \\
\hline & 7.50 & 5.66 & 4.57 & 3.82 & \\
\hline$\Pi_{1}^{f}\left(I_{1}^{f^{*}}, I_{2}^{f^{*}}, I_{3}^{f^{*}}, \bar{x}\right)$ & -0.30 & -0.30 & -0.30 & -0.30 & 1.5 \\
\hline$\left.I_{2}^{f^{*}}, I_{3}^{f^{*}}, \bar{x}\right)$ & -0.30 & -0.30 & -0.30 & -0.30 & \\
\hline$\left.I_{2}^{f^{*}}, I_{3}^{f^{*}}, \bar{x}\right)$ & 64.10 & 67.77 & 69.96 & 71.45 & \\
\hline$\Pi\left(I_{1}^{f^{*}}, I_{2}^{f^{*}}, I_{3}^{f^{*}}, \bar{x}\right)$ & 63.50 & 67.17 & 69.36 & 70.85 & \\
\hline & 0 & 0 & 0 & 0 & \\
\hline & 0 & 0 & 0 & 0 & \\
\hline & 6.16 & 4.57 & 3.62 & 2.98 & \\
\hline$\left.f_{2}^{*}, I_{3}^{f^{*}}, \bar{x}\right)$ & -0.30 & -0.3 & -0.30 & -0.3 & 2.0 \\
\hline$\Pi_{2}^{f}\left(I_{1}^{f^{* *}}, f_{2}^{f^{* *}}, I_{3}^{f^{*}}, \bar{x}\right)$ & -0.30 & -0.3 & -0.30 & -0.3 & \\
\hline$\Pi_{3}^{f}\left(I_{1}^{f^{* *}}, f_{2}^{f^{*}}, I_{3}^{f^{*}}, \bar{x}\right)$ & 66.78 & 69.96 & 71.85 & 73.15 & \\
\hline$\Pi\left(I_{1}^{f^{*}}, I_{2}^{f^{*}}, I_{3}^{f^{*}}, \bar{x}\right)$ & 66.18 & 69.36 & 71.25 & 72.55 & \\
\hline f* & 0 & 0 & 0 & 0 & \\
\hline$I_{2}^{f^{*}}$ & 0 & 0 & 0 & 0 & \\
\hline$I_{3}^{f^{*}}$ & 5.25 & 3.82 & 2.98 & 2.40 & \\
\hline$\left.I_{3}^{f^{*}, \bar{x}}\right)$ & -0.30 & -0.30 & -0.30 & -0.30 & 2.5 \\
\hline$\Pi_{2}^{f}\left(I_{1}^{f^{* *}}, f_{2}^{f^{* *}}, I_{3}^{f^{*}}, \bar{x}\right)$ & -0.30 & -0.30 & -0.30 & -0.30 & \\
\hline$\Pi_{3}^{f}\left(I_{1}^{f^{* *}}, f_{2}^{f^{* *}}, f_{3}^{f^{*}}, \bar{x}\right)$ & 68.61 & 71.45 & 73.15 & 74.30 & \\
\hline$\Pi\left(I_{1}^{f^{*}}, I_{2}^{f^{*}}, I_{3}^{f^{*}}, \bar{x}\right)$ & 68.01 & 70.85 & 72.55 & 73.70 & \\
\hline
\end{tabular}

Table 7: Numerical example for negotiated scheme $f$

\begin{tabular}{|c|c|c|c|c|c|}
\hline & \multicolumn{4}{|c|}{$a_{1}$} & \multirow[b]{2}{*}{$a_{2}$} \\
\hline & 1.0 & 1.5 & 2.0 & 2.5 & \\
\hline$\omega_{2}$ & 5.05 & 5.72 & 6.40 & 7.08 & \\
\hline$f^{f^{*}}$ & 2.91 & 2.41 & 1.91 & 1.41 & \\
\hline & 2.91 & 2.91 & 2.91 & 2.91 & \\
\hline & 0 & 0 & 0 & 0 & \\
\hline$\Pi_{1}^{f}\left(I_{1}^{f^{*}}, I_{2}^{f^{*}}, I_{3}^{f^{*}}, \bar{x}\right)$ & 41.40 & 37.90 & 34.40 & 30.90 & 1.0 \\
\hline$\Pi_{2}^{f}\left(I_{1}^{f^{*}}, I_{2}^{f^{*}}, I_{3}^{f^{*}}, \bar{x}\right)$ & 29.85 & 33.85 & 37.85 & 41.85 & \\
\hline$\Pi_{3}^{f}\left(I_{1}^{f^{*}}, I_{2}^{f^{*}}, I_{3}^{f^{*}}, \bar{x}\right)$ & 0 & 0 & 0 & 0 & \\
\hline$\Pi\left(I_{1}^{f^{*}}, f_{2}^{f^{*}}, f_{3}^{f^{*}}, \bar{x}\right)$ & 71.26 & 71.76 & 72.26 & 72.76 & \\
\hline & 5.61 & 6.34 & 7.08 & 7.82 & \\
\hline & 2.91 & 2.41 & 1.91 & 1.41 & \\
\hline & 2.41 & 2.41 & 2.41 & 2.41 & \\
\hline & 0 & 0 & 0 & 0 & \\
\hline$\Pi_{1}^{f}\left(I_{1}^{f^{*}}, I_{2}^{f^{*}}, I_{3}^{f^{*}}, \bar{x}\right)$ & 41.40 & 37.90 & 34.40 & 30.90 & 1.5 \\
\hline$\Pi_{2}^{f}\left(I_{1}^{f^{*}}, I_{2}^{f^{*}}, I_{3}^{f^{*}}, \bar{x}\right)$ & 30.35 & 34.35 & 38.35 & 42.35 & \\
\hline$\Pi_{3}^{f}\left(I_{1}^{f^{*}}, I_{2}^{f^{*}}, I_{3}^{f^{*}}, \bar{x}\right)$ & 0 & 0 & 0 & 0 & \\
\hline$\Pi\left(I_{1}^{f^{*}}, I_{2}^{f^{*}}, f_{3}^{f^{*}}, \bar{x}\right)$ & 71.76 & 72.26 & 72.76 & 73.26 & \\
\hline & 6.28 & 7.09 & 7.90 & 8.72 & \\
\hline & 2.91 & 2.41 & 1.91 & 1.41 & \\
\hline & 1.91 & 1.91 & 1.91 & 1.91 & \\
\hline & 0 & 0 & 0 & 0 & \\
\hline$\left.f_{2}^{f^{*}}, I_{3}^{f^{*}}, \bar{x}\right)$ & 41.40 & 37.90 & 34.40 & 30.90 & 2.0 \\
\hline$\Pi_{2}^{f}\left(I_{1}^{f^{*}}, I_{2}^{f^{*}}, I_{3}^{f^{*}}, \bar{x}\right)$ & 30.85 & 34.85 & 38.85 & 42.85 & \\
\hline$\Pi_{3}^{f}\left(I_{1}^{f^{*}}, I_{2}^{f^{*}}, I_{3}^{f^{*}}, \bar{x}\right)$ & 0 & 0 & 0 & 0 & \\
\hline$\Pi\left(I_{1}^{f^{*}}, I_{2}^{f^{*}}, I_{3}^{f^{* *}}, \bar{x}\right)$ & 72.26 & 72.76 & 73.26 & 73.76 & \\
\hline 0 & 7.10 & 8.01 & 8.91 & 9.82 & \\
\hline & 2.91 & 2.41 & 1.91 & 1.41 & \\
\hline & 1.41 & 1.41 & 1.41 & 1.41 & \\
\hline 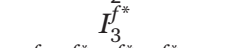 & 0 & 0 & 0 & 0 & \\
\hline$\left.I_{2}^{f^{*}}, I_{3}^{f^{*}}, \bar{x}\right)$ & 41.40 & 37.90 & 34.40 & 30.90 & 2.5 \\
\hline$\Pi_{2}^{f}\left(I_{1}^{f^{*}}, I_{2}^{f^{*}}, I_{3}^{f^{*}}, \bar{x}\right)$ & 31.35 & 35.35 & 39.35 & 43.35 & \\
\hline$\Pi_{3}^{f}\left(I_{1}^{f^{*}}, I_{2}^{f^{*}}, I_{3}^{f^{*}}, \bar{x}\right)$ & 0 & 0 & 0 & 0 & \\
\hline$\Pi\left(I_{1}^{f^{*}}, I_{2}^{f^{*}}, f_{3}^{f^{* *}}, \bar{x}\right)$ & 72.76 & 73.26 & 73.76 & 74.26 & \\
\hline
\end{tabular}

\section{Appendix C: Additional explanations for Section $\mathbf{4 . 3}$}

This appendix provides further explanations concerning the negotiations under transfer pricing based on full costs presented in Section 4.3. In particular, we first motivate why negotiated transfer pricing does not maximize (expected) total profit and then why the downstream division is not considered in the analysis of the negotiations.

At first glance, it might be surprising that, as a result of our analysis, negotiated transfer pricing is inefficient with respect to total profit, see Propositions 1 and 6. One might rather expect that the three divisions agree on maximizing total 
profit by choosing appropriate investments and divide the maximal total profit among themselves by means of the transfer prices. While this course of action would produce Pareto-efficient (expected) divisional profits, it is only feasible either if investments are contractible or if, given the agreed transfer prices, it is in each division's individual interest not to deviate from the agreed investments. In our setting, the investment decisions, $I_{i}$, are not contractible; only the investments' actual costs, $C_{i}$, are. Since the investment decision only determines the investment's expected actual costs, the investment decision cannot be inferred from actual investment costs. Consequently, it is not feasible to maximize total profit by contracting the investment decisions themselves or by a forcing contract based on the associated investment costs. Enforceability of an agreement on investments therefore requires that it is a Nash equilibrium in the noncooperative investment game arising from the simultaneous investment choices at date 3. Since the downstream division does not invest in equilibrium, see Proposition 3, first-best investments as given by Proposition 1 do not form an equilibrium and transfer pricing based on full costs does not achieve first best.

In our model, negotiating investment levels for positive markups basically means that the divisions select one out of multiple equilibria in the investment game. Each of these equilibria has the property that the downstream division's contribution margin is zero, see expression (12). To see this refer to Figure 3 and concentrate on the pair $\omega$ of markup factors. Assume that $D_{2}$ invests $I_{2}^{f b}(0)$ and remember that Figure 3 is based on zero investment for $D_{3}$. Then, $D_{1}$ 's best reaction to $I_{2}=I_{2}^{f b}(0)$ and $I_{3}=0$ is $I_{1}=I_{1}^{f b}(0)$. The corresponding profit for $D_{1}$ is approximately 7.4. Any higher investment implies that $D_{3}$ expects a negative contribution margin and thus does not market the product, which leads to a negative profit for $D_{1}$. Investing less is not optimal for $D_{1}$ either: For instance, for $I_{1}=I_{1}^{f b}(0) / 2$ the profit for $D_{1}$ amounts to approximately 4.7 , while the corresponding contribution margin for $D_{3}$ is positive.

Increasing $D_{1}$ 's investment then means higher (expected) revenue for $D_{3}$ due to the investment's positive effect on the sales price. Yet, the associated increase of the (expected) transfer payment to $D_{1}$ is even higher. Thus, increasing $I_{1}$ lowers $D_{3}$ 's contribution margin, while $D_{1}$ 's profit increases. $D_{3}$ 's contribution margin is just exhausted and $D_{1}$ 's profit is maximized, when $I_{1}$ reaches $I_{1}^{f b}(0)$. Equivalent effects govern $D_{1}$ 's optimal reaction to other investment levels chosen by $D_{2}$ and $D_{3}$, and also apply for $D_{2}$ 's optimal investment reaction. Hence, in any equilibrium of the investment game, $D_{3}$ incurs zero contribution margin. It is therefore not worthwhile for this division to invest, so that, in equilibrium, $D_{3}$ incurs zero profit. Since this result holds for any pair of positive markup factors, there is no effect of $D_{3}$ taking part in the negotiations, neither on the investment levels nor on the markup factors.

\section{Acknowledgments}

The authors acknowledge comments received at the EAA conference in Gothenburg, the conference of the German Operations Research Society in Karlsruhe, and the conference of the German Academic Association for Business Research (VHB) in Dresden. Further beneficial recommendations have been given by workshop participants at the Otto-von-Guericke-University Magdeburg. We would like to thank two anonymous referees and Rainer Niemann (the department editor). Their comments helped to significantly clarify the paper.

\section{References}

Anctil, Regina M. and Sunil Dutta (1999): Negotiated Transfer Pricing and Divisional vs. Firm-Wide Performance Evaluation, The Accounting Review, 74 (1): 87-104.

Baldenius, Tim (2000): Intrafirm Trade, Bargaining Power, and Specific Investments, Review of Accounting Studies, 5 (1): 27-56.

Baldenius, Tim, Stefan Reichelstein, and Savita A. Sahay (1999): Negotiated versus Cost-Based-Transfer Pricing, Review of Accounting Studies, 4 (2): 67-91.

Che, Yeon-Koo and Donald B. Hausch (1999): Cooperative Investments and the Value of Contracting, The American Economic Review, 89 (1): 125-147.

Chwolka, Anne and Dirk Simons (2003): Impacts of Revenue Sharing, Profit Sharing and Transfer Pricing on QualityImproving Investments, European Accounting Review, 12 (1): 47-76.

Czechowicz, I. James, Frederick D. S. Choi, and Vinod B. Bavishi (1982): Assessing Foreign Subsidiary Performance: Systems \& Practices Of Leading Multinational Companies, Business International Corporation: New York (New York).

Drury, Colin (2004): Management and Cost Accounting, 6th ed., Thomson Learning: London. 
Eccles, Robert G. (1985): The Transfer Pricing Problem: A Theory for Practice, Lexington Books: Lenham.

Edlin, Aaron S. and Stefan Reichelstein (1995): Specific Investment under Negotiated Transfer Pricing: An Efficiency Result, The Accounting Review, 70 (2): 275-291.

Edlin, Aaron S. and Stefan Reichelstein (1996): Holdups, Standard Breach Remedies, and Optimal Investment, The American Economic Review, 86 (3): 478-501.

Ernst \& Young (2001): Transfer Pricing 2001 Global Survey, Ernst \& Young International Limited, http://www2.eycom.ch/ publications/items/transfpric/en.pdf (Access date: 2003-0903).

Ernst \& Young (2003): Transfer Pricing 2003 Global Survey, EYGM Limited, http://webappo1.ey.com.pl/EYP/ WEB/eycom_download.nsf/resources/Transfer\%20Pricing\% 20Survey\%20Report_2003.pdf/\$FILE/Transfer\%20Pricing\% 20Survey\%20Report_2003.pdf (Access date: 2005-06-23).

Grabski, Severin V. (1985): Transfer Pricing in Complex Organizations: A Review and Integration of Recent Empirical and Analytical Research, Journal of Accounting Literature, 4: 33-75.

Holmstrom, Bengt and Jean Tirole (1991): Transfer Pricing and Organizational Form, The Journal of Law, Economics, and Organization, 7 (2): 201-228.

Horngren, Charles T., Srikant M. Datar, and George Foster (2005): Cost Accounting: A Managerial Emphasis, 12th ed., Pearson Prentice Hall: Upper Saddle River (NJ).

Johnson, Nicole Bastian (2006): Divisional Performance Measurement and Transfer Pricing for Intangible Assets, Review of Accounting Studies, 11 (2/3): 339-365.

Lengsfeld, Stephan, Thomas Pfeiffer, and Ulf Schiller (2006): Centralized versus Decentralized Transfer Pricing and CostSystem Choice, Working Paper, SSRN.

Myerson, Roger B. (1981): Utilitarianism, Egalitarianism, and the Timing Effect in Social Choice Problems, Econometrica, 49 (4): 883-897.

Nash, John F. (1950): The Bargaining Problem, Econometrica, 18 (2): 155-162.

Nash, John F. (1953): Two-Person Cooperative Games, Econometrica, 21 (1): 128-140.

OECD (1999): Transfer Pricing Guidelines for Multinational Enterprises and Tax Administrations, Organisation for Economic Co-operation and Development (OECD): Paris.

Sahay, Savita A. (2003): Transfer Pricing Based on Actual Cost, Journal of Management Accounting Research, 15(1): 177-192.

Simon, Hermann (1989): Price Management, North-Holland: Amsterdam.

Tang, Roger Y. W. (1993): Transfer Pricing in the 1990s: Tax and Management Perspectives, Quorum Books: Westport.

Wielenberg, Stefan (2000): Negotiated Transfer Pricing, Specific Investment, and Optimal Capacity Choice, Review of Accounting Studies, 5 (3): 197-216.

\section{Biographies}

Anne Chwolka has held the Chair of Business Economics and Accounting at the Otto-vonGuericke-University Magdeburg since 2004. She received her Diploma in Managerial Economics and her Doctoral degree at Bielefeld University, where she also completed her Habilitation. Her research interests include decision analysis, internal pricing, risk reporting, and performance measurement.

Jan Thomas Martini, MA, Diplom-Kaufmann, Dr., is a postdoctoral research and teaching associate at the Chair of Management Accounting and Operations Management at Bielefeld University (Germany). He graduated in International Business at ESC Rennes School of Business (France) and in Business Administration at Bielefeld University, from which he also received a doctoral degree. His research interests include managerial accounting, in particular transfer pricing, industrial services, and the links between managerial accounting on the one hand and financial accounting and taxation on the other.

Dirk Simons has been Professor and Chair of Business Administration \& Accounting at Mannheim University since 2004 and Head of the Center of Doctoral Studies in Business Administration since 2008. He studied Business Administration and received his Diploma Degree at Bielefeld University, where he also received his doctorate and achieved his Habilitation. His main fields of research are theory of accounting and auditing, applied institutional economics, international accounting, and convergence of managerial and financial accounting. 